\title{
Ceramide synthesis regulates T cell activity and GVHD development
}

\author{
M. Hanief Sofi, ${ }^{1}$ Jessica Heinrichs, ${ }^{1}$ Mohammed Dany, ${ }^{2}$ Hung Nguyen, ${ }^{1}$ Min Dai, ${ }^{1}$ David Bastian, ${ }^{1}$ \\ Steven Schutt, ${ }^{1}$ Yongxia Wu, ${ }^{1}$ Anusara Daenthanasanmak, ${ }^{1}$ Salih Gencer, ${ }^{2}$ Aleksandra Zivkovic, ${ }^{3}$ \\ Zdzislaw Szulc, ${ }^{2}$ Holger Stark, ${ }^{3}$ Chen Liu, ${ }^{4}$ Ying-Jun Chang, ${ }^{5}$ Besim Ogretmen, ${ }^{2}$ and Xue-Zhong Yu ${ }^{1}$ \\ 'Department of Microbiology and Immunology and 'Department of Biochemistry and Molecular Biology, Medical University \\ of South Carolina, Charleston, South Carolina, USA. ${ }^{3}$ Institute of Pharmaceutical and Medicinal Chemistry, Heinrich \\ Heine University Düsseldorf, Duesseldorf, Germany. ${ }^{4}$ Department of Pathology and Laboratory Medicine, Rutgers-Robert \\ Wood Johnson Medical School, New Brunswick, New Jersey, USA. ${ }^{5}$ Peking University People's Hospital and Institute of \\ Hematology, Beijing, China.
}

Allogeneic hematopoietic cell transplantation (allo-HCT) is an effective immunotherapy for a variety of hematologic malignances, yet its efficacy is impeded by the development of graftversus-host disease (GVHD). GVHD is characterized by activation, expansion, cytokine production, and migration of alloreactive donor T cells. Hence, strategies to limit GVHD are highly desirable. Ceramides are known to contribute to inflammation and autoimmunity. However, their involvement in T-cell responses to alloantigens is undefined. In the current study, we specifically characterized the role of ceramide synthase 6 (CerS6) after allo-HCT using genetic and pharmacologic approaches. We found that CerS6 was required for optimal T cell activation, proliferation, and cytokine production in response to alloantigen and for subsequent induction of CVHD. However, CerS6 was partially dispensable for the T cell-mediated antileukemia effect. At the molecular level, CerS6 was required for efficient TCR signal transduction, including tyrosine phosphorylation, ZAP-70 activation, and PKC $\theta /$ TCR colocalization. Impaired generation of C16-ceramide was responsible for diminished allogeneic $\mathrm{T}$ cell responses. Furthermore, targeting CerS6 using a specific inhibitor significantly reduced $\mathrm{T}$ cell activation in mouse and human $\mathrm{T}$ cells in vitro. Our study provides a rationale for targeting CerS6 to control GVHD, which would enhance the efficacy of allo-HCT as an immunotherapy for hematologic malignancies in the clinic.

Conflict of interest: The authors have declared that no conflict of interest exists.

Submitted: November 11, 2016 Accepted: April 18, 2017 Published: May 18, 2017

Reference information: JCI Insight. 2017;2(10):e91701. https:// doi.org/10.1172/ji.i.insight.91701

\section{Introduction}

Graft-versus-host disease (GVHD) is a major complication occurring after allogeneic hematopoietic stem cell transplantation (HSCT). GVHD manifests itself as a progressive, systemic disease that mostly affects the intestines, liver, lung, and skin (1). Despite significant improvements in patient care, GVHD development remains the major limiting factor in the success of allogeneic hematopoietic cell transplantation (alloHCT) for the treatment of hematologic malignancies, leading to significant transplant-related morbidity and mortality (2). GVHD is characterized by the increased production of inflammatory cytokines and activation and expansion of alloreactive donor $\mathrm{T}$ cells in conjunction with the failure of existing regulatory mechanisms to counterbalance this proinflammatory milieu (3-5). Patient conditioning regimens as well as Th1-type cytokines produced by allogeneic $\mathrm{T}$ cells are the driving forces contributing to the initiation and development of GVHD (2-6). Thus, strategies designed to impede the pathogenesis of GVHD by regulating alloreactive donor $\mathrm{T}$ cell expansion and inflammatory cytokine productions are highly desirable.

Sphingolipids are highly bioactive molecules that can greatly influence cellular signaling and disease pathogenesis (6). Currently, they are known mediators of apoptosis, proliferation, growth arrest, and inflammation (7). Ceramides form the backbone to several complex sphingolipids, such as sphingomyelins and glucosylceramides, which can be generated by de novo synthesis or by degradation of complex sphingolipids. A key rate-limiting step in the biosynthesis of ceramides is the attachment of various acylCoA side chains to a sphingoid base by ceramide synthases. The ceramide synthases (CerS1-CerS6) act in a chain length- specific manner and introduce side chains to form C14-C30 ceramides. Briefly, CerS1 synthesizes C18-Cer, CerS4 synthesizes C18-/C20-Cer, CerS5 and CerS6 primarily synthesize C16-Cer, 
CerS2 mainly synthesizes C22/C24-Cer, and CerS3 synthesizes ultra-long-chain ceramides (8). In addition to de novo synthesis, the salvage pathway also supplies ceramides, mainly via the activation of sphingomyelinases (SMase) (7).

Although T cell metabolism, such as glycolysis and oxidative phosphorylation, has been studied extensively (9), sphingolipid metabolism in T cell activation and function is much less characterized. Recent findings indicate that ceramides play important roles in inflammatory processes, and it has been shown that host acid SMase are imperative for maximal GVHD-associated pathology (10). In the aforementioned study, lack of host acid SMase reduced the acute inflammatory phase of GVHD, attenuating the cytokine storm (10). In the inflammatory disease cystic fibrosis, ceramides induce the upregulation of proinflammatory mediators, albeit via an unknown mechanism (11). Importantly, CerS6-generated ceramides were shown to specifically contribute to the inflammatory process in the initial phase of experimental autoimmune encephalomyelitis (EAE) (12). Thus, evidence exists to support the role of specific ceramides in inflammatory processes $(12,13)$. However, the role of CerS6-generated ceramides in modulating $\mathrm{T}$ cell alloresponses in GVHD and graft-versus-leukemia (GVL) activity has not been elucidated. In the current study, we demonstrate that the absence of CerS6 in donor T cells significantly reduces GVHD. This reduction in GVHD was correlated with reduced $\mathrm{T}$ cell proliferation and responses of proinflammatory cytokines, namely IFN- $\gamma$. Mechanistically, we observed that CerS6 is critical for optimal TCR signal transduction and defects in CerS6 expression lead to reduced tyrosine phosphorylation and CD3-PKC $\theta$ colocalization. Furthermore, application of the CerS6/S4 inhibitor, ST1072, was used to confirm its role in $\mathrm{T}$ cell proliferation and proinflammatory cytokine production both in mouse and human cells after allostimulation. Thus, our study provides biological insights into the function of CerS6 as well as rationale to target CerS6 for the control GVHD after allogeneic BM transplantation (allo-BMT).

\section{Results}

CerS6 promotes allogeneic $T$ cell responses. Ceramide syntheses play a critical role in inflammatory processes $(12,14)$ and are involved in many autoimmune diseases $(12,15)$. However, how ceramide syntheses regulate activation and function of primary $\mathrm{T}$ cells is largely undefined. To address this question, we initially evaluated the role of CerS4 and CerS6 in T cell responses. For this purpose, we characterized T cell development and phenotype in WT, CerS4 KO, and CerS6 KO mice on a B6 background. In the thymus, while $\mathrm{T}$ cell compartments were similar in WT and CerS4 $\mathrm{KO}$ mice, a significant increase in percentages of CD4 $\mathrm{CD}^{+}$and $\mathrm{CD}^{+} \mathrm{CD}^{2} 5^{+} \mathrm{Foxp}^{+}$cells was observed in CerS6 KO mice (Supplemental Figure 1, A and B; supplemental material available online with this article; https://doi.org/10.1172/jci.insight.91701DS1). In the spleen, CerS6 KO mice had a higher percentage of $\mathrm{CD}^{+}$cells, but not Tregs, as compared with WT and CerS4 KO controls (Figure 1, A and B). Furthermore, percentages of naive T cells (CD44-CD62L ${ }^{+}$) were decreased, whereas effector memory T cells $\left(\mathrm{CD} 44^{+} \mathrm{CD} 62 \mathrm{~L}^{-}\right)$were increased in CerS6 KO mice (Figure 1, $\mathrm{C}$ and D). These data suggest that CerS6, not CerS4, affects T cell development and function. Because of the different percentages of memory T cells and Tregs, we purified naive T cells by negative selection. After purification, the percentages of naive $\mathrm{T}$ cells $\left(\mathrm{CD} 25^{-} \mathrm{CD} 44^{-} \mathrm{CD} 62 \mathrm{~L}^{+}\right)$were comparable between $\mathrm{WT}$ and CerS KO cells. Hereafter, we used CD44/CD25-depleted T cells throughout the following experiments.

Ceramides are critical for inflammatory responses (16). In the inflammatory disease cystic fibrosis, ceramides induce the upregulation of proinflammatory mediators (11). In addition, C16-ceramide (C16cer) generated by CerS6 is involved in the induction of EAE through activation of NO/TNF- $\alpha$ synthesis (12). Therefore, we next sought to test whether, or how, CerS6 or CerS4 affects T cell activation and function. Upon alloantigen stimulation in vitro, CerS6 $\mathrm{KO} \mathrm{T}$ cells, both $\mathrm{CD}^{+}$and $\mathrm{CD} 8^{+}$, had a substantially reduced ability to proliferate and produce IFN- $\gamma$ compared with WT counterparts, as reflected by the percentage of CFSE-diluted cells (Supplemental Figure 2, A and C) and the percentage of IFN- $\gamma^{+} \mathrm{T}$ cells (Supplemental Figure 2, B and D). In contrast, CerS4 $\mathrm{KO} \mathrm{CD} 4^{+} \mathrm{T}$ cells proliferated faster while $\mathrm{CD}^{+}$ $\mathrm{T}$ cells proliferated slower than their WT counterparts (Supplemental Figure 2, E-G); no difference was observed in IFN- $\gamma$ production between CerS4 KO and WT T cells (Supplemental Figure 2, F-H). These results prompted us to evaluate $\mathrm{T}$ cell responses in vivo. Upon transfer of $\mathrm{T}$ cells into irradiated allogeneic recipients, we observed that the CerS6 KO, but not the CerS4 KO, T cells significantly reduced proliferation and IFN- $\gamma$ production compared with WT counterparts (Figure 2). In contrast, CerS4 KO T cells had a comparable response to WT T cells. These results suggest that CerS6, but not CerS4, is required for optimal $\mathrm{T}$ cell proliferation and activation in response to alloantigens. To test whether CerS6 deficiency leads to 

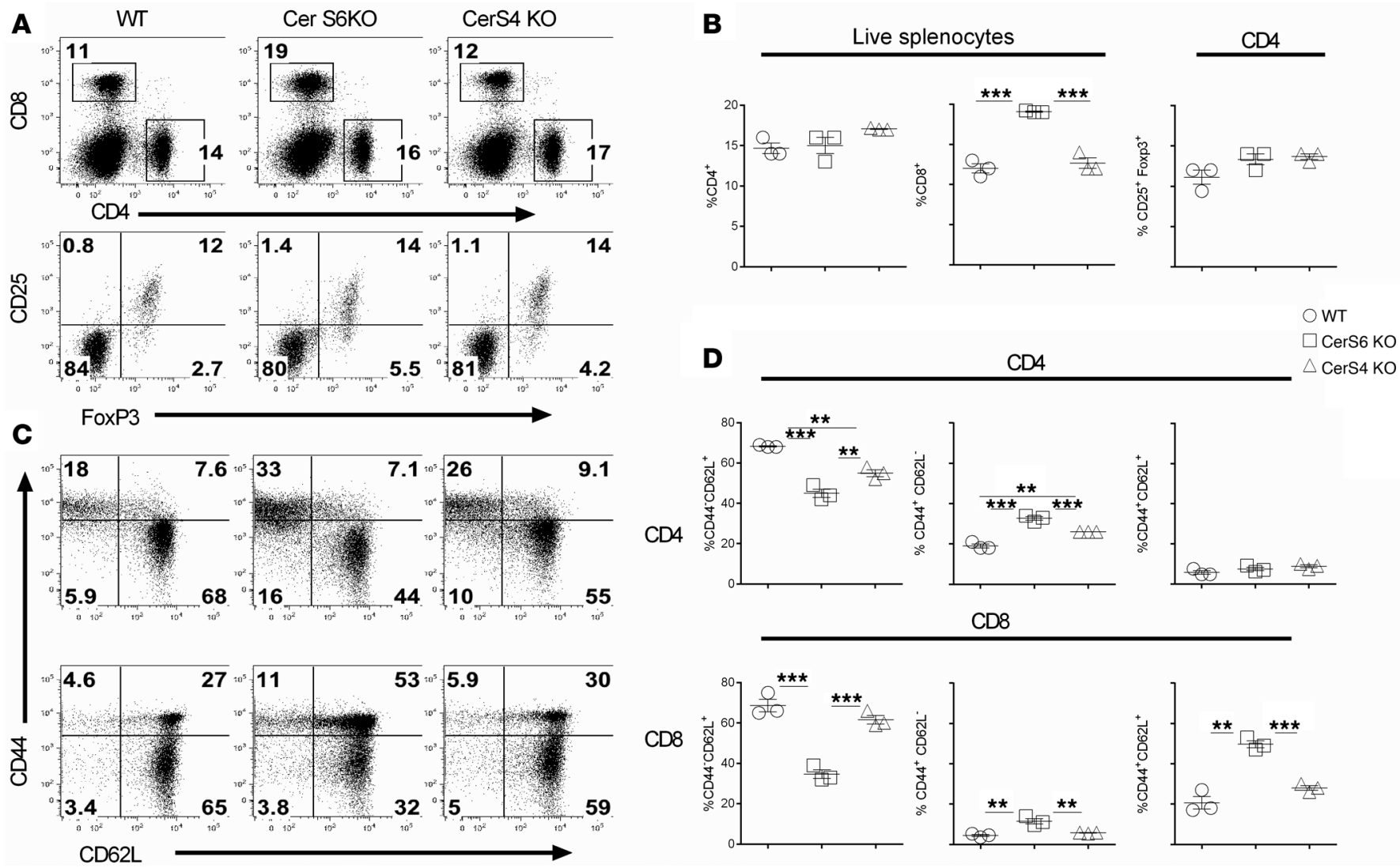

Figure 1. Effects of ceramide synthase 4 or ceramide synthase 6 on T cell phenotype. Spleens were obtained from unmanipulated age- and sex-matched WT, ceramide synthase 4 (CerS4) KO, or ceramide synthase 6 (CerS6) KO mice on a B6 background. Splenocytes were individually processed, counted, and stained for the expression of CD4, CD8, Foxp3, CD44, and CD62L. (A and B) Percentages of CD4+ ${ }^{+}$or CD8 ${ }^{+}$cells on total live splenocytes, percentages of $\mathrm{CD}^{2} 5^{+} \mathrm{Foxp}^{+}$cells on gated CD4+ cells, and (C and $\left.\mathbf{D}\right)$ CD44 and CD62L expression on gated CD4+ ${ }^{+}$or CD8 ${ }^{+}$cells are shown. (A and $\left.\mathbf{C}\right)$ Data shown are from 1 representative mouse. The data are from 1 representative experiment of 3 independent experiments (mean \pm SD with 3 mice per group). Significance was determined by using ANOVA test. ${ }^{* *} P<0.01,{ }^{* * *} P<0.001$.

global impairment of $\mathrm{T}$ cell response, we transferred purified $\mathrm{T}$ cells from WT or CerS6 KO donors into lethally irradiated syngeneic recipients. Under homeostatic responses, T cells deficient in CerS6 proliferated equally well as compared with WT counterparts, as reflected by CSFE dilution (Supplemental Figure 3, A and B) or/and absolute number of donor T cells (Supplemental Figure 3, C and D), which indicates that CerS6 is not required for $\mathrm{T}$ cell activity globally.

CerS6 is essential for T cells to induce GVHD. Given that CerS6 KO T cells displayed a reduced allogeneic response in vitro and in vivo, we further hypothesized that CerS6 is essential for T cells to induce GVHD. Since naive and memory T cells have a distinct ability to induce GVHD and the proportion of naive and memory $\mathrm{T}$ cells was different in CerS6 $\mathrm{KO}$ and WT controls (Figure 1), we removed CD44 $4^{+}$memory $\mathrm{T}$ cells prior to BMT and compared naive $\mathrm{T}$ cells in the subsequent experiments. In a major MHC-mismatched $\mathrm{B} 6 \rightarrow \mathrm{BALB} / \mathrm{c}$ BMT model, we found that recipients of WT $\mathrm{T}$ cells developed severe and lethal GVHD, whereas the majority of the recipients of CerS6 KO T cells survived long term and had significantly less weight loss and a reduced clinical score (Figure 3A). We have done this analysis extensively and substantiated the effect of CerS6 on different strains of mice by using a haploidentical BMT model. Similar results were also observed in a clinically relevant, haploidentical BMT model (B6 $\rightarrow$ BD2F1) (Figure 3B). In contrast, CerS4 KO T cells had a comparable ability to WT T cells to induce GVHD (Figure 3). Taken together, CerS6 positively regulates both $\mathrm{T}$ cell responses to alloantigen and GVHD development.

Given that CerS4 had no observable effect on T cell allogeneic response and GVHD development, we decided to focus exclusively on the role of CerS6 in T cells and GVHD from this point forward. To test whether CerS6 affects T cell-mediated GVL activity, we infused host-type B cell lymphoma (A20) together with $\mathrm{BM}$ or BM plus $\mathrm{T}$ cells into BALB/c recipients. As expected, all the recipients without $\mathrm{T}$ cell infusion 
A

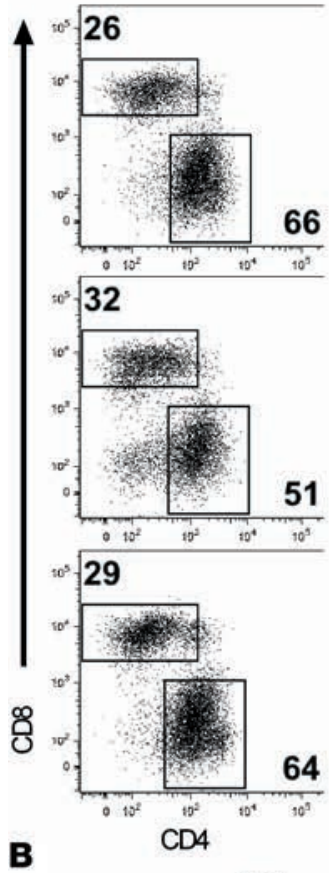

CD4

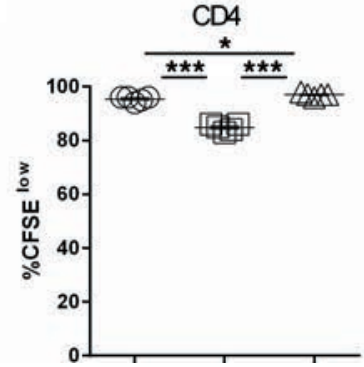

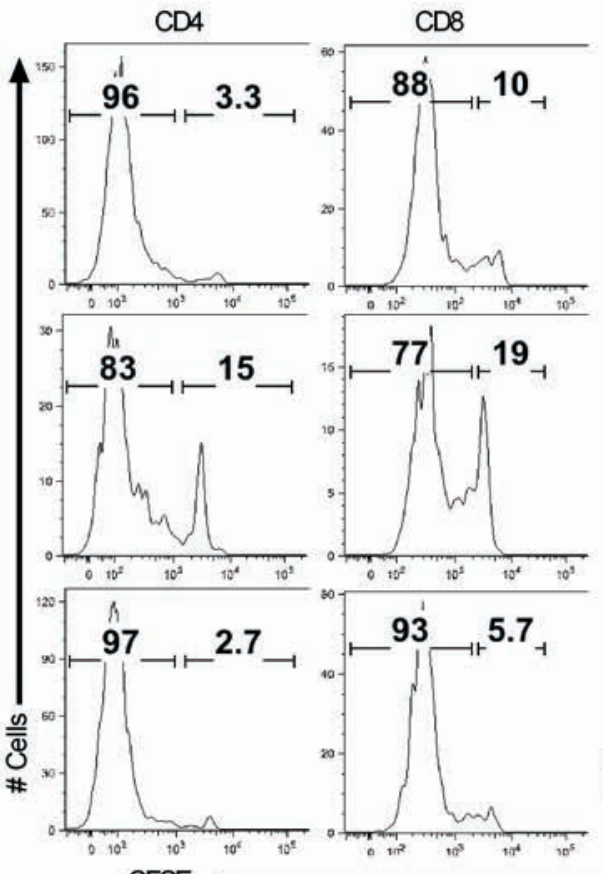
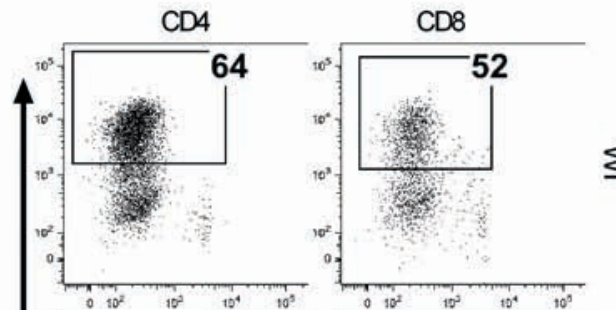

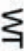

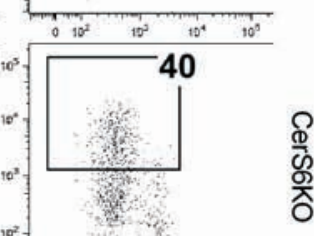

$\mathrm{CD} 4$

$\mathrm{CD} 8$
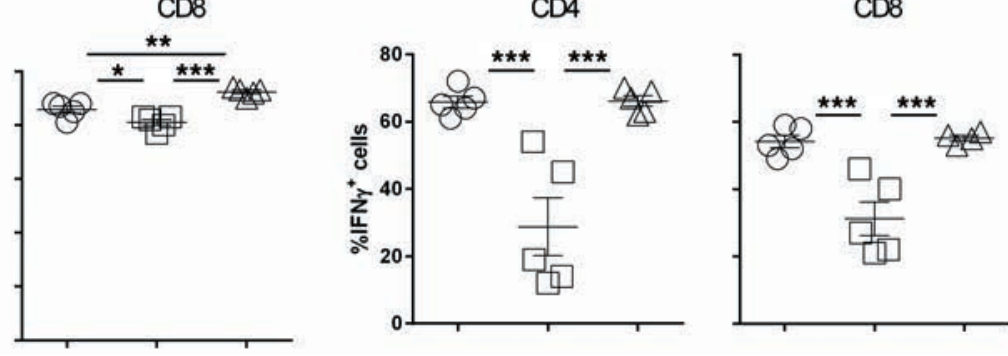

OWT

$\square$ CerS6Ka

$\triangle$ CerS4KO

Figure 2. Role of ceramide synthase $\mathbf{6}$ in T cell response to alloantigen in vivo. Purified T cells from WT, ceramide synthase 4 (CerS4) KO, or ceramide synthase 6 (CerS6) KO mice on a B6 background were labeled with CFSE and i.v. injected into lethally irradiated BALB/c mice at $2 \times 10^{6}$ per mouse. Four days after cell transfer, spleens were collected from recipient mice and subjected to cell counting and FACS staining. (A) Percentages of donor-derived ( $\left.\mathrm{H} 2 \mathrm{~K}^{\mathrm{b}+}\right) \mathrm{CD} 4^{+}$and $\mathrm{CD} 8^{+}$ cells among gated live cells and representative flow figures of CFSE dilution and IFN- $\gamma^{+}$cells on gated donor CD4+ or CD8 ${ }^{+}$cells. (B) Percentages of CFSE diluted and IFN- $\gamma^{+}$cells on gated donor $\mathrm{CD} 4^{+}$and $\mathrm{CD}^{+}$cells. Error bars represent one standard deviation in each group. Data shown are replicate of 2 independent experiments. Significance was determined by using ANOVA test. ${ }^{*} P<0.05,{ }^{* *} P<0.01,{ }^{* *} P<0.001$.

died of lymphoma relapse within 30 days after BMT (Figure 4B). The recipients of WT T cells died from GVHD, as reflected by survival (Figure 4B), body weight loss (Figure 4A), clinical scores (Figure 4C), and tumor signal (Figure 4D). In contrast, $45 \%-50 \%$ recipients of CerS6 KO T cells survived without GVHD and were largely free from tumor relapse. Taken together, these data suggest that the CerS6 KO T cells were partially able to preserve GVL activity in an MHC-mismatched BMT model.

CerS6 regulates $T$ cell expansion and migration. Development of GVHD requires donor T cell expansion in lymphoid organs and migration into target organs (17). Hence, we asked whether CerS6 is required for $\mathrm{T}$ cell infiltration and expansion into target organs. Three weeks after BMT, we observed that recipients of CerS6 KO T cells had significantly fewer pathological injuries in the liver and colon (Figure 5A), which was consistent with the GVHD outcome presented in Figure 3. We next examined the presence of donor $\mathrm{T}$ cells in recipient spleens (secondary lymphoid organ) and livers (GVHD target organ) 3 weeks after allo-BMT. Comparable numbers of CerS6 KO and WT T cells were found in recipient spleens (Figure 5, B-F); although a lower percentage of CerS6 KO T cells produced IFN- $\gamma$, suggesting that the CerS6 KO T cells had a reduced ability to differentiate into Th1 cells. In contrast, a significantly lower number of CerS6 $\mathrm{KO} \mathrm{CD} 4^{+} \mathrm{T}$ cells was found in recipient livers as compared with that of WT T cells. In addition, T cells that migrated into the liver expressed significantly reduced levels 
A

B6

BALB/C
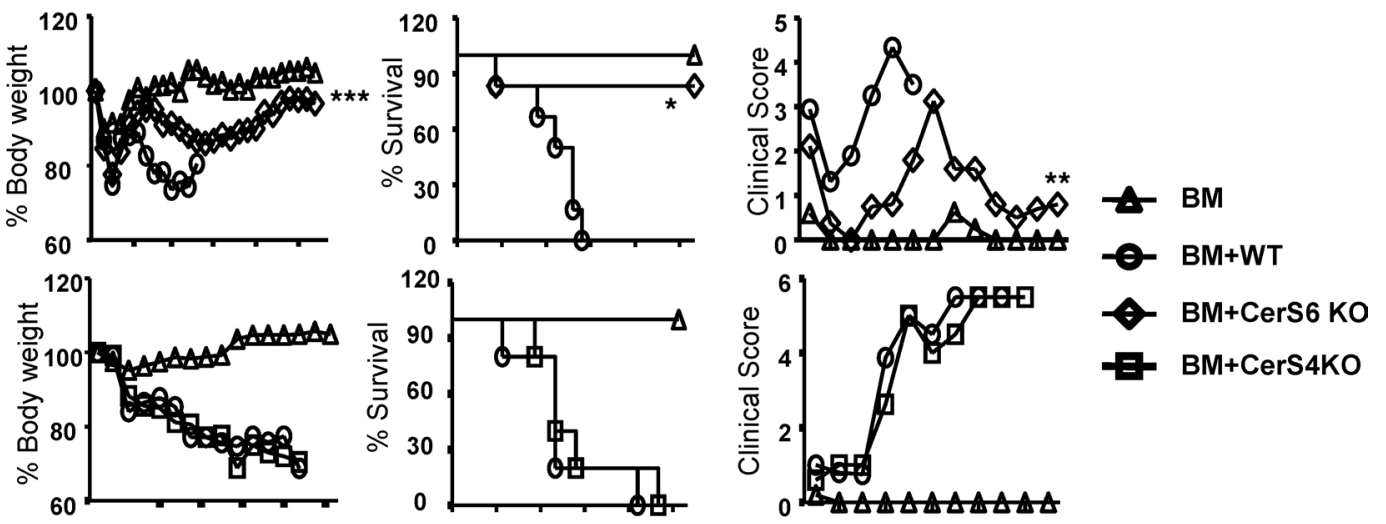

B

\section{B6}

BDF1
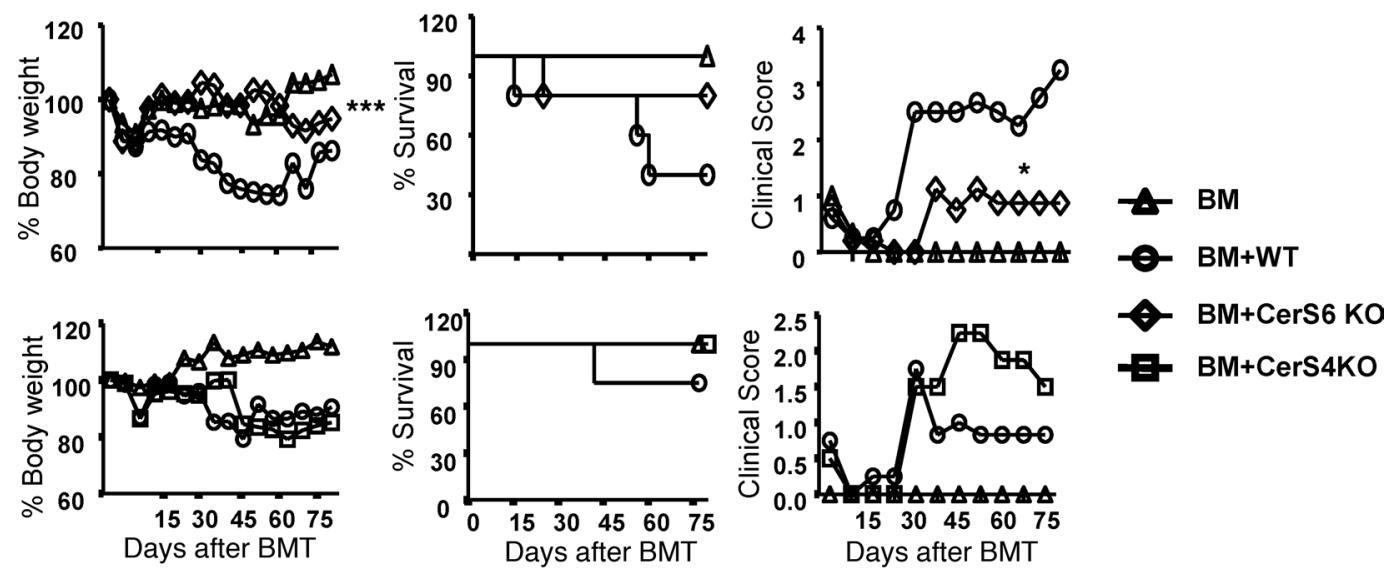

Figure 3. Essential role of ceramide synthase 6 in T cell-induced graft-versus-host disease. (A) BALB/C or (B) BD2F1 mice were lethally irradiated and transplanted with $5 \times 10^{6}$ T cell-depleted BM cells (Ly5.1 $\left.1^{+}\right)$per mouse or BM plus purified T cells (Ly5.2+) $\left(0.5 \times 10^{6} / \mathrm{mouse}\right.$ for BALB/C or $2 \times 10^{6} /$ mouse for BD2F1) from WT, ceramide synthase 4 (CerS4) KO, or ceramide synthase 6 (CerS6) KO B6 mice. BALB/c and BDF1 recipients were monitored for body weight change, survival, and clinical score until 80 days after BMT ( $n=5$ per group). Data shown are from 1 of 3 independent experiments for $B A L B / c$ mice. For comparison of recipient survival among groups, the log-rank test was used to determine statistical significance. Clinical scores and body weight loss were compared using a nonparametric Mann-Whitney $U$ test. ${ }^{*} P<0.05,{ }^{* *} P<0.01$.

of IFN- $\gamma$ in the CerS6 KO group. However, levels of IL-4/5 and Foxp3 were similar regardless of CerS6 expression. Similar results were found on donor $\mathrm{CD} 8^{+} \mathrm{T}$ cells, although to a lesser extent (Figure 5, D and $\mathrm{F}$ ). These data suggest that CerS6 $\mathrm{KO} \mathrm{T}$ cells may reduce expansion and/or migration.

CerS6 is essential for T cells to induce colitis. Thus far, we have presented evidence that CerS6 regulates $\mathrm{T}$ cell activation in alloresponses. To expand upon the regulatory role of CerS6 in $\mathrm{T}$ cells beyond solely investigating the alloresponse, we asked whether CerS6 can regulate T cells in an autoimmune setting using a mouse model of colitis. By transferring naive $\mathrm{CD} 4^{+} \mathrm{T}$ cells into lymphopenic $\mathrm{Rag} 1^{-1^{-}}$hosts $(18,19)$, we observed that the recipients of CerS6 KO T cells developed significantly less severe colitis compared with recipients of WT T cells, as reflected by body weight loss, colon length, and colitis score (Supplemental Figure 4, A-C). Consistent with colitis scores, significantly lower numbers of CerS6 KO T cells migrated into the colon compared with WT T cells (Supplemental Figure 4, D-G). Although T cells that infiltrated into the colon produced comparable levels of IFN- $\gamma$ or IL-17 regardless of CerS6 expression, the total number of IFN- $\gamma$ - or IL-17-producing T cells was significantly lower in CerS6 KO cells than in WT T cells (Supplemental Figure 4, D-G). These data indicate that CerS6 may also play a critical role in regulating $\mathrm{T}$ cell responses in other autoimmune diseases.

Proximal TCR signaling is impaired in CerS6 KO T cells. TCR signaling dictates T cell response to cognate antigen. At the molecular level, we asked whether CerS6 affects TCR signaling. To address 
A

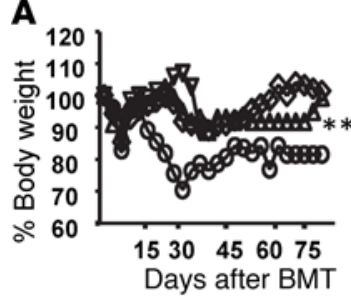

D

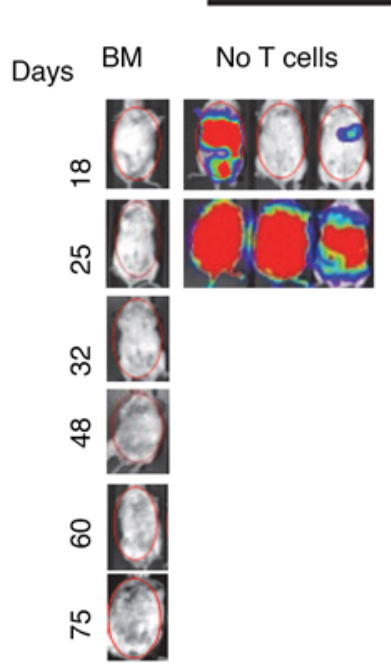

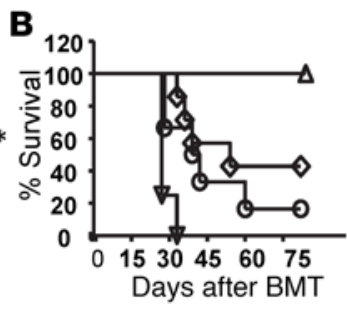

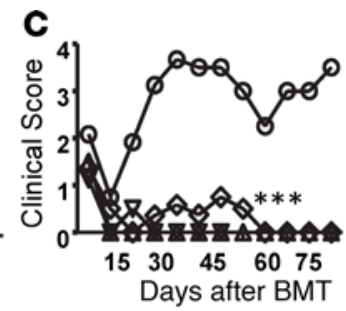

$\mathrm{BM}+\mathrm{A} 20$

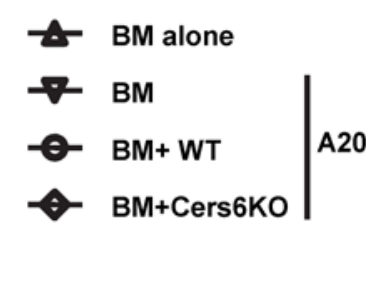

A20

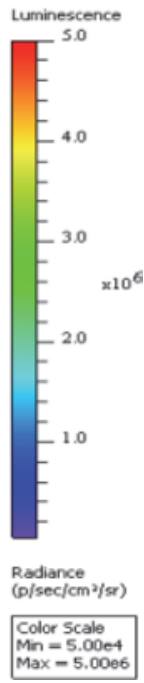

Figure 4. Effect of ceramide synthase 6 on T cell-mediated-CVL activity. B cell lymphoma was infused with BM or BM plus $0.5 \times 10^{6} /$ mouse T cells into lethally irradiated allogeneic recipients. Mice were monitored for (A) body weight, (B) survival, (C) clinical score, and (D) tumor signal. Data shown are from 1 of 2 independent experiments ( $n=6-7$ per group for WT and CerS6 KO). For comparison of recipient survival among groups, the log-rank test was used to determine statistical significance. Clinical scores and body weight loss were compared using a nonparametric Mann-Whitney $U$ test. ${ }^{* * *} P<0.001$.

this question, we stimulated WT and CerS6 KO splenocytes with anti-CD3 at various time points and measured total tyrosine phosphorylation. CerS6 KO T cells had reduced levels of tyrosine phosphorylation compared with WT T cells (Figure 6A), suggesting that TCR signaling was impaired in the absence of CerS6. Similarly, we observed that tyrosine phosphorylation of a 70-kDa protein was impaired in the CerS6 KO cells after anti-CD3 stimulation (Figure 6A) and reasoned that it was ZAP-70, a key kinase for TCR signal transduction. Indeed, ZAP-70 was strongly phosphorylated and associated with $\mathrm{CD} 3 \zeta$ after TCR stimulation in WT, but not CerS6 KO (Figure 6B). T cell activation is associated with translocation of PKC $\theta$ from the cytosol to the membrane $(20,21)$. It is also reported that PKC $\theta$ can translocate to membrane rafts and that these rafts localize to the synapse formed upon contact between $\mathrm{T}$ cells and APCs (22). We therefore asked if CerS6 affects PKC $\theta$ expression and colocalization with the TCR. Upon stimulation with anti-CD3, more PKC $\theta$ colocalized with CD3 in WT T cells than in CerS6 KO T cells (Figure 6, C and D). These data indicate that CerS6 affects $\mathrm{T}$ cell activation and function by regulating early TCR signaling.

Effect of CerS6 KO on lipid metabolism. The data presented thus far indicate that CerS6 is critical for optimal $\mathrm{T}$ cell activation and function. We sought to investigate how CerS6 affects sphingolipid metabolism during $\mathrm{T}$ cell response. Using a comprehensive lipidomics analysis, we found that $\mathrm{C} 16$-cer was the only sphingolipid metabolite that significantly increased after allostimulation in WT T cells; yet this increase was not present in CerS6 KO T cells (Figure 7A).

Furthermore, since we observed that CerS6 was required for optimal TCR signaling (Figure 6), we asked whether lack of C16-cer was responsible for impaired TCR signaling in CerS6 KO T cells. To address this question, a gain-of-function approach was used, in which synthesized C16-cer was added into the cell culture. While additional $\mathrm{C} 16$-cer had little or no effect on $\mathrm{CD} 3 / \mathrm{PKC} \theta$ colocalization in WT $\mathrm{T}$ cells (Figure 7B vs. Figure 6C), it dramatically increased CD3/PKC $\theta$ colocalization in CerS6 KO T cells, especially at 15 minutes after TCR stimulation (Figure 7C vs. Figure 6D). The data suggest that an 
A

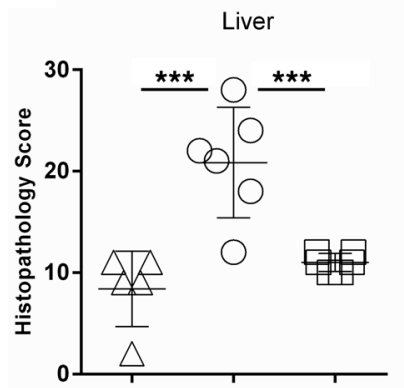

B

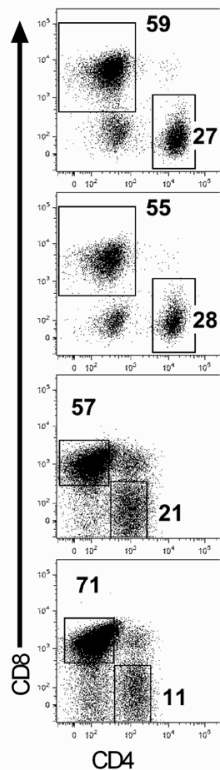

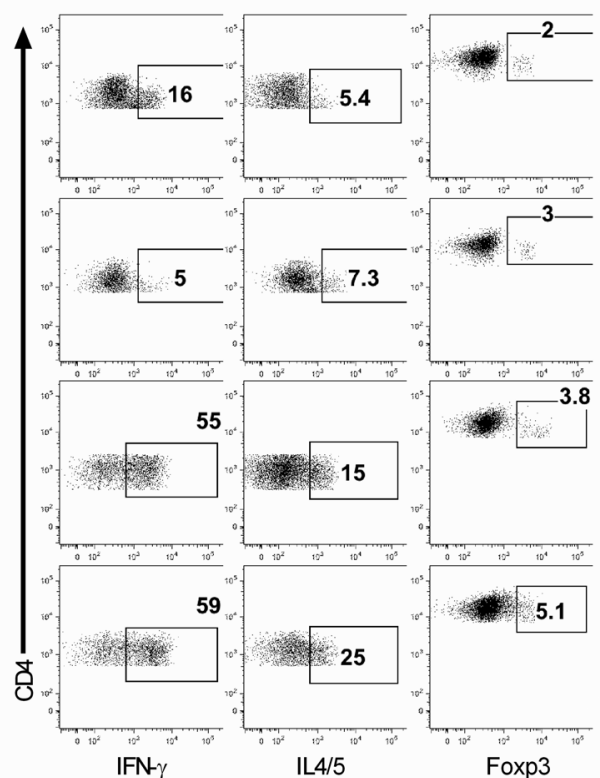

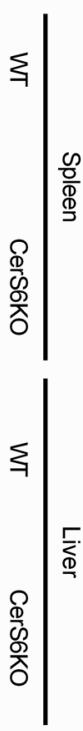

C

$\triangle$ BM $\bigcirc$ WT $\square$ Cers6Ko

$\mathrm{CD} 4$

D

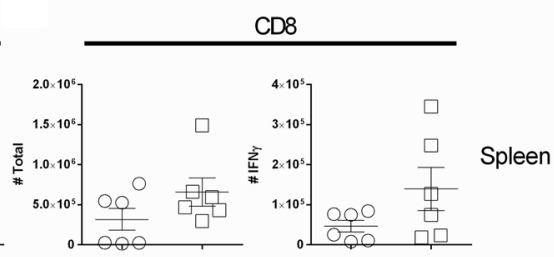

$\mathbf{F}$

E
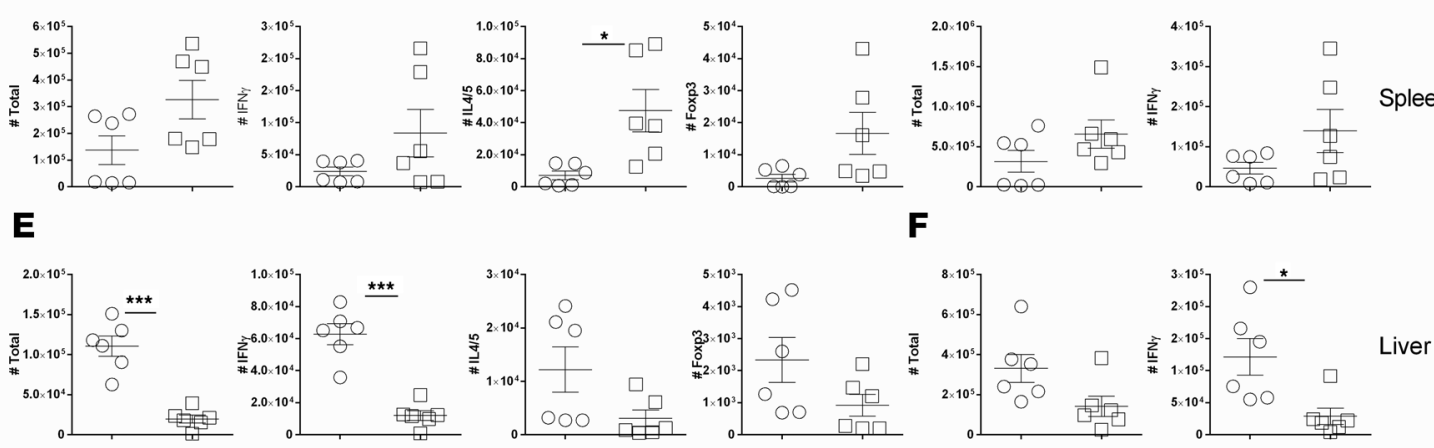

Figure 5. Effect of ceramide synthase $\mathbf{6}$ on donor T cell differentiation after allo-BMT. BMT was carried out as outlined in Figure 3 using BALB/C mice as the recipients. Three weeks after BMT, livers and colons were collected from the recipients for H\&E staining and were scored for microscopic GVHD severity by a pathologist blinded to the treatment groups. Data on small intestine, lung, and skin are not shown. (A) Pathological score of GVHD target organs (mean \pm SD). (B) Recipient spleen and liver cells were subjected to cell counting and FACS staining. The expression of IFN- $\gamma$, IL-4/5, or Foxp3 on gated $\mathrm{H}_{2} \mathrm{~K}^{\mathrm{b}+}$ donor $\mathrm{CD} 4^{+}$or $\mathrm{CD} 8^{+}$cells from a representative mouse from each group. (C and $\left.\mathbf{D}\right)$ The absolute numbers of $(\mathbf{C})$ IFN- $\gamma^{+}$, IL-4/5+, and Foxp3 $3^{+}$donor $\mathrm{CD} 4^{+}$ cells and (D) $\mathrm{CD}^{+}\left(\mathrm{H} 2 \mathrm{~K}^{\mathrm{b}+} \mathrm{Ly} 5.1^{-}\right)$cells in recipient spleens and (E and $\left.\mathbf{F}\right)$ for livers, respectively. Data shown are from 2 independent experiments $(n=6)$. Significance was determined by ANOVA $(\mathbf{A})$ and Student's $t$ tests (for $\mathbf{C}$ and $\mathbf{D})$. ${ }^{*} P<0.05,{ }^{*} P<0.01,{ }^{* *} P<0.001$.

inability to increase C16-cer might be responsible for the impaired function of CerS6 KO T cells (Figures 2, 5, and 6 and Supplemental Figure 4).

C16-cer affects $T$ cell proliferation and cytokine production. To further define the effect of C16-cer on $\mathrm{T}$ cell activation and function, we tested whether $\mathrm{C} 16$-cer could restore the $\mathrm{T}$ cell response in CerS6-deficient $\mathrm{T}$ cells. Indeed, additional C16-cer restored the proliferation capacity of CerS6 $\mathrm{KO} \mathrm{CD4} 4^{+} \mathrm{T}$ cells to that of WT counterparts in vitro (Supplemental Figure 5). To extend this observation to $\mathrm{T}$ cell responses in vivo, we transplanted WT or CerS6 KO T cells into irradiated allogeneic recipients and tested the effect of C16cer administration. Consistent with in vitro results, C16-cer increased proliferation of CerS6 KO T cells, although not significantly, given that allogeneic T cells proliferated much faster in vivo (Figure 8, A-C). Albeit, C16-cer significantly increased the percentage of IFN- $\gamma^{+}$cells in both $\mathrm{CD}^{+}$and $\mathrm{CD} 8^{+} \mathrm{T}$ cells in CerS6 KO, but not WT, T cells (Figure 8, D and E). These results indicate that CerS6 is required for optimal $\mathrm{T}$ cell activation, proliferation, and cytokine production in allogeneic responses to C16-cer. 
A

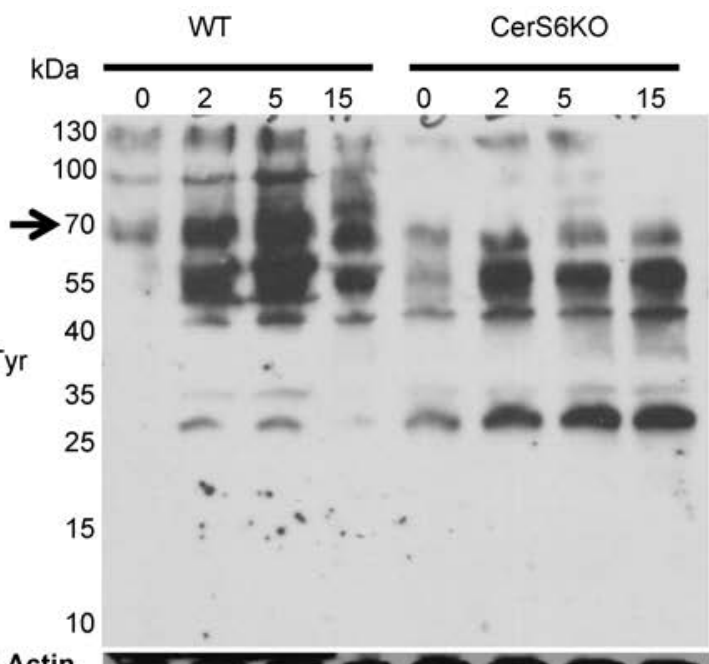

B minutes

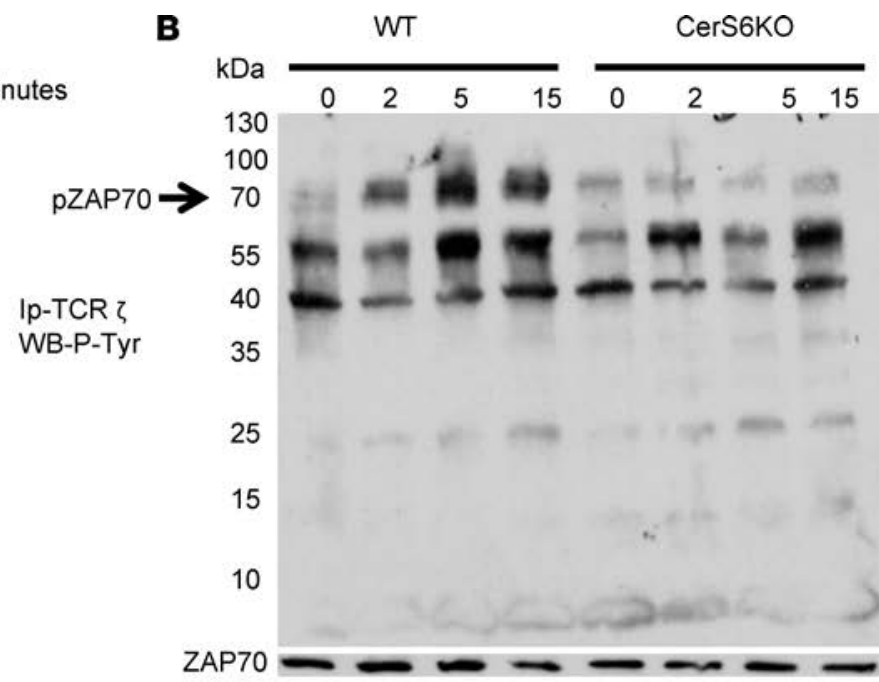

C
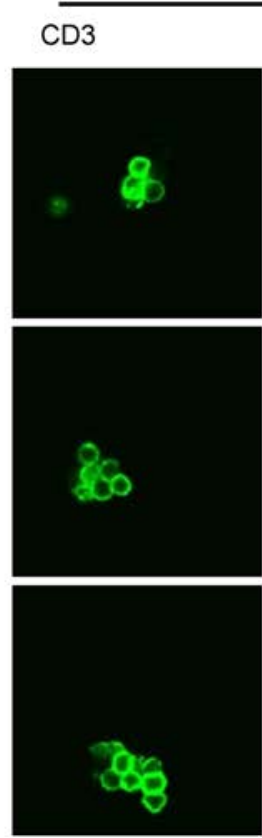

WT

$$
\text { PKC } \theta
$$
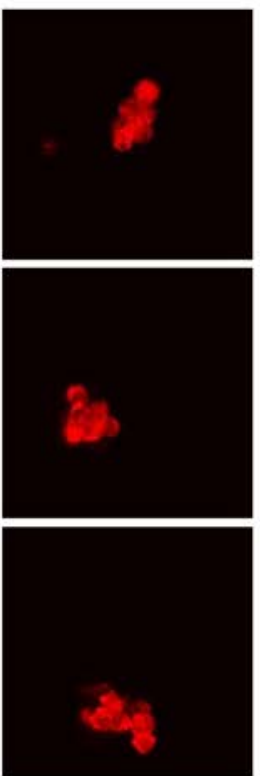

Overlay
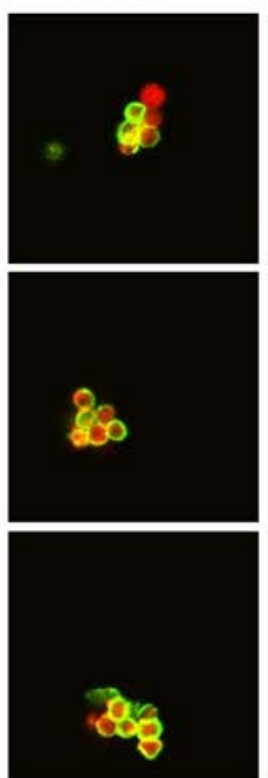

D

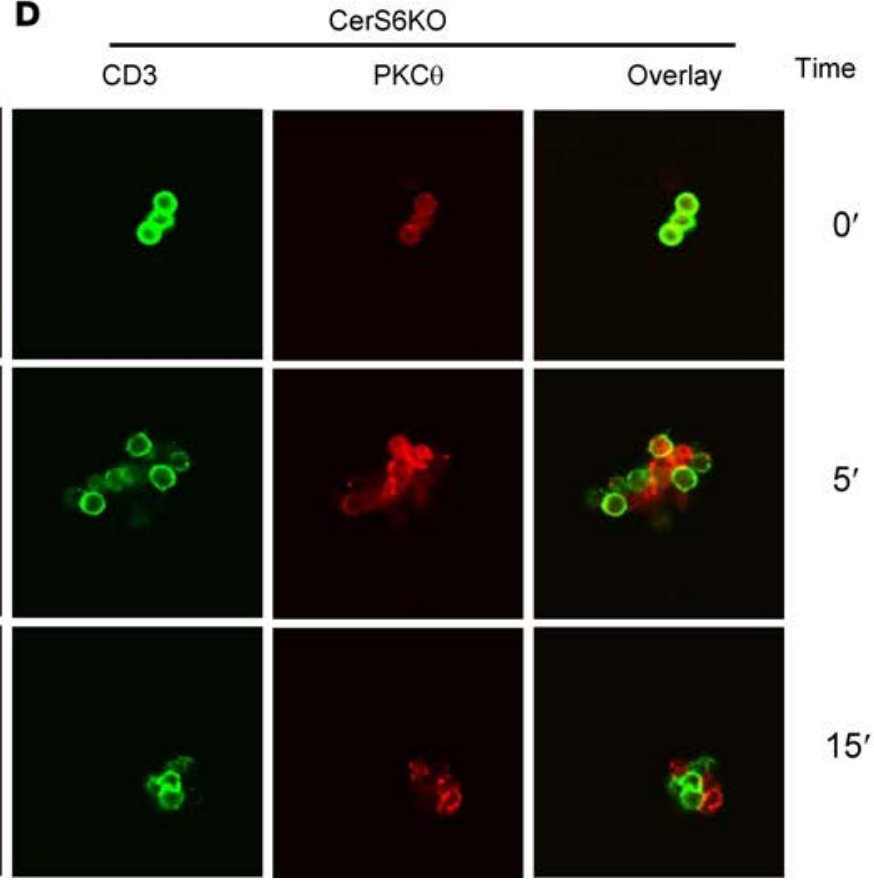

Figure 6. Role of ceramide synthase 6 in proximal TCR signaling. (A) Western blot was performed using cell lysates prepared from freshly isolated splenocytes before and after TCR engagement at the indicated time points. The membrane was probed with an antibody detecting total phosphotyrosine, stripped, and reprobed with anti- $\beta$ actin. (B) CD3 $\zeta$ material was immunoprecipitated from WT or ceramide synthase 6 (CerS6) KO T cells before and after TCR engagement. The presence of coimmunoprecipitated protein was then evaluated by Western blot using total phosphotyrosine. (C and D) Splenocytes were subjected to TCR engagement for the indicated time points and stained for CD3 and PKC $\theta$ expression followed by analysis with confocal microscopy (original magnification, $\times 63$ ). At least 4-5 fields in each condition per experiment were examined. Data shown are 1 representative of 3 independent experiments.

Inhibition of CerS6 reduces $T$ cell response to alloantigen. We have demonstrated that CerS6 promotes $T$ cell responses to alloantigen and thus GVHD development. We hypothesized that pharmacologic inhibition of CerS6 would have a similar effect on allogeneic $\mathrm{T}$ cell responses. To test this hypothesis, we evaluated the effect of the CerS6/S4 inhibitor, ST1072 (23), on T cell responses after allogeneic stimulation. As shown in Figure 9, ST1072 significantly reduced the ability of murine T cells to proliferate (Figure 9, A and C) and produce IFN- $\gamma$ (Figure 9, B and D). To assess the specificity of ST1072, we tested its effect on CerS6 KO T cell responses after allogeneic stimulation. While ST1072 inhibited cell proliferation of WT T cells in a dose-dependent manner, it had a minimal effect on CerS6 KO T cells (Supplemental Figure 6, A and B). 


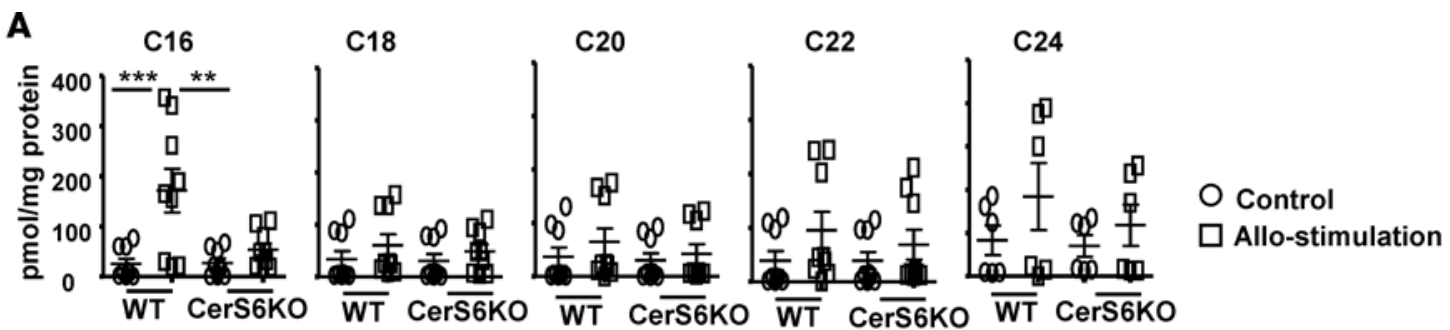

B
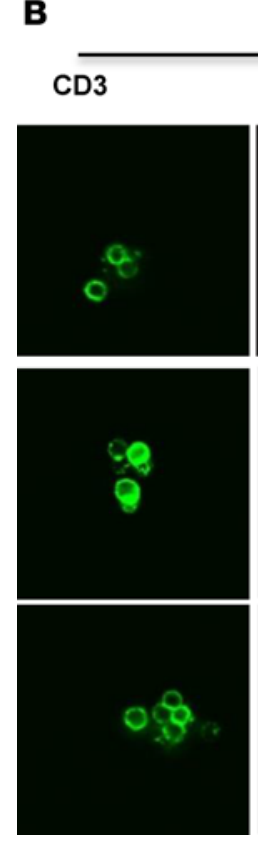

WT

PKC $\theta$
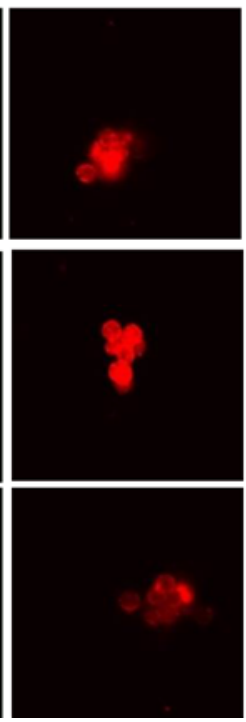

C

Overlay
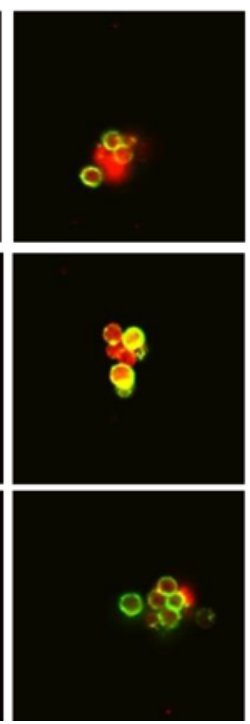

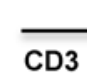

CerS6Ko
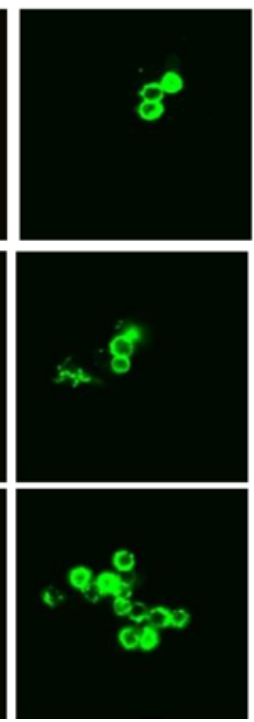

PKC $\theta$
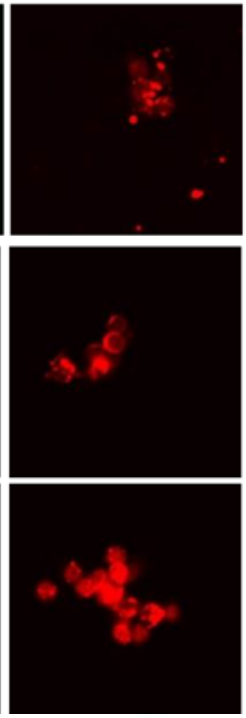

Overlay Time

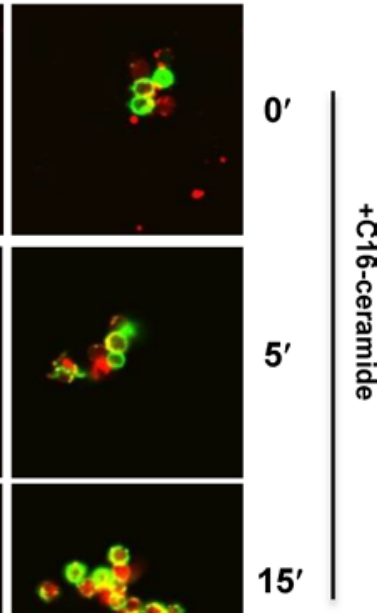

$15^{\prime}$

Figure 7. Effect of ceramide synthase 6 on lipid metabolism. (A) T cells from WT or ceramide synthase 6 (CerS6) KO mice were stimulated with allogeneic APCs for 5 days, and unstimulated T cells were used as controls. These T cells were subjected to mass spectrometry HPLC-MS analysis for different ceramide species. Data shown are from 3 independent experiments $(n=9)$. Splenocytes from (B) WT or (C) CerS6 KO mice were incubated with C16-cer for 1 hour at $37^{\circ} \mathrm{C}$ and were either left unstimulated or subjected to TCR engagement for the indicated time points. Cells were then stained for CD3 and PKC $\theta$ expression, followed by analysis with confocal microscopy (original magnification, $\times 63$ ). Data shown are from 1 representative experiment of 3 independent experiments. Significance was determined by ANOVA test. ${ }^{* *} P<0.01,{ }^{* *} P<0.001$.

For translational purposes, we sought to extend this observation to human T cells. Consistent with the observed results in murine T cells, we found that inhibition of CerS6/S4 significantly lowered the proliferation and IFN- $\gamma$ production of human $\mathrm{CD} 4^{+} \mathrm{T}$ cells in response to alloantigen stimulation in vitro (Figure 9, E-G). These results indicate that CerS6 can be pharmacologically targeted to regulate $\mathrm{T}$ cell activation and function.

\section{Discussion}

Sphingolipids are known to play essential roles in the induction and progression of inflammation (24), but how specific ceramides regulate inflammation and immune responses is largely undefined $(12,13)$. To our knowledge, we show for the first time that CerS6 and its product C16-cer contribute to inflammation by inducing $\mathrm{T}$ cell proliferation and IFN- $\gamma$ production. In addition, we found that CerS6 ablation reduced $\mathrm{T}$ cell alloresponses in the initial phases of GVHD and also that targeting this molecule is efficacious in reducing the severity of colitis, implying that CerS6 blockade could be therapeutically applicable to autoimmune disorders. Using primarily genetic and pharmacologic approaches, our data demonstrate that CerS6 governs multiple aspects of the T cell response to alloantigen, though not under hemostatic conditions. CerS6 strongly enhances activation and proliferation of $\mathrm{T}$ cells, and the expression of CerS6 on donor T cells is essential for the induction of GVHD after allo-BMT. Hence, pharmacologic blockade (using ST1072) 
A
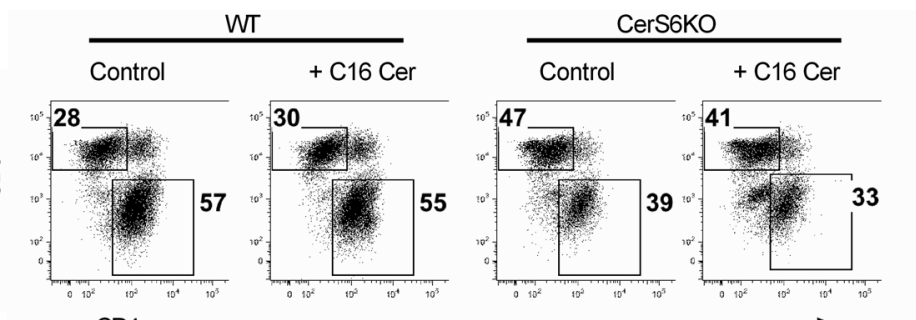

B

CD4
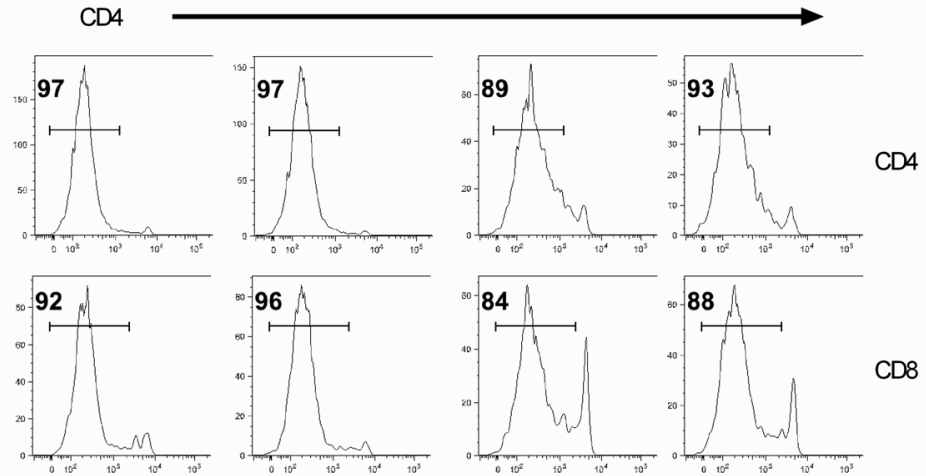

D
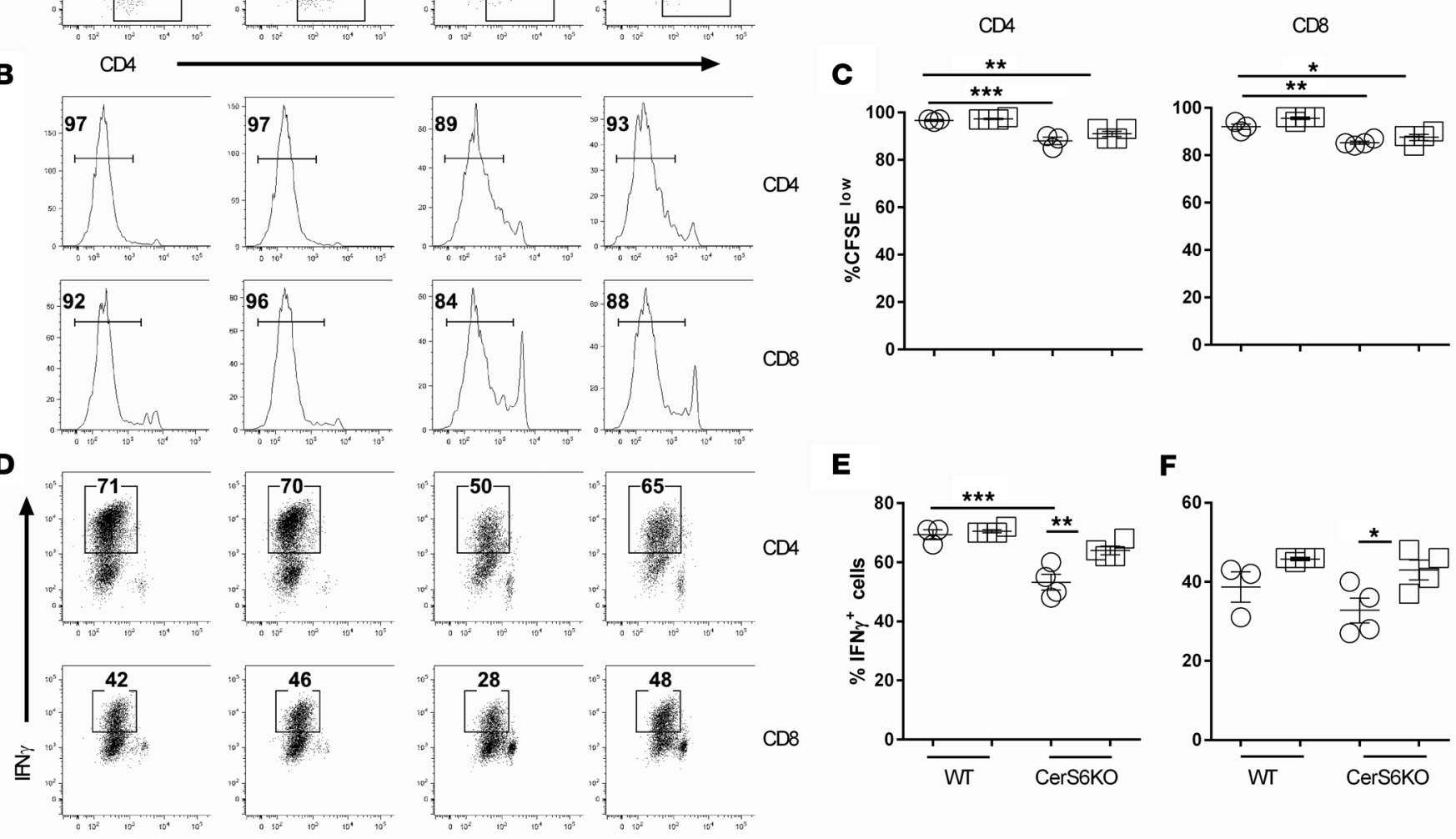

E

F

CD4
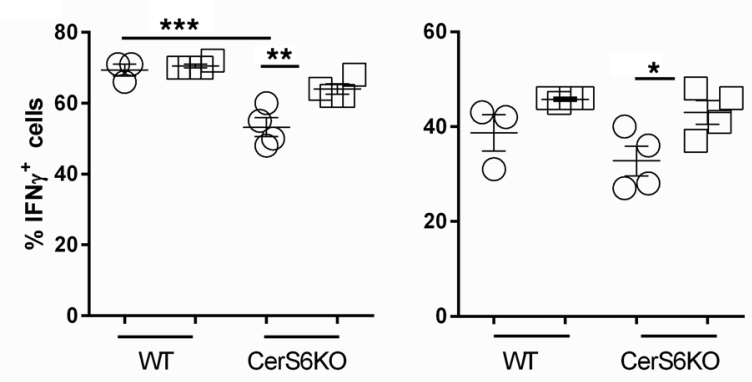

CFSE

Figure 8. Effect of C16-ceramide on T cell proliferation and cytokine expression. Purified T cells from WT or ceramide synthase 6 (CerS6) KO mice were labeled with CFSE and i.v. injected into lethally irradiated BALB/c recipients at $2 \times 10^{6} /$ mouse. Recipients were also injected intraperitoneally at $15 \mathrm{mg} /$ $\mathrm{kg}$ with C16-ceramide or vehicle from day 1 to day 3. Four days after cell transfer, recipient spleens were collected and subjected to cell counting and FACS

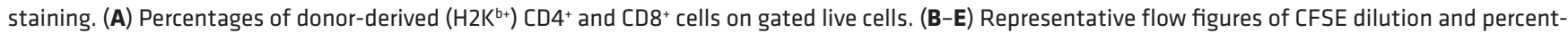
ages of IFN- $\gamma^{+}$cells on gated donor CD4+ and CD8 $8^{+}$cells (mean \pm SD of 3-4 mice per group). Data shown are from 1 representative experiment of 2 independent experiments. Significance was determined by ANOVA test for (C, E, and $\mathbf{F}) .{ }^{*} P<0.05,{ }^{* *} P<0.01,{ }^{* *} P<0.001$.

of CerS6 represents a potential approach for attenuating GVHD in a clinical setting. Mechanistically, T cells deficient in CerS6 had a dramatically decreased ability to expand, which correlated with a reduced proliferation capacity during alloantigen-driven responses in vivo. This observed reduction in proliferation can be linked to reduced tyrosine phosphorylation and impaired colocalization of CD3-PKC $\theta$ (Figure 6, A-C) in CerS6 KO T cells after TCR stimulation. From these data, it is plausible to predict that inhibition of CerS6 could specifically, or preferentially, suppress alloantigen-driven responses while preserving $\mathrm{T}$ cell homeostasis, a highly coveted benefit that would alleviate GVHD without causing broad immune suppression in patients undergoing allo-HCT.

T cell phenotypes are critical to GVHD pathogenesis. Previous studies have shown that donor memory $\mathrm{T}$ cells alone are incapable of inducing $\operatorname{GVHD}(25,26)$, while naive $\mathrm{CD} 4 \mathrm{~T}$ cells possess an enhanced ability to cause GVHD $(25,26)$. Hypothetically, the TCR repertoire could be altered such that the immunodominant miHAs targeted by naive T cells are not recognized by memory cells (26). CerS6 KO naive donor $\mathrm{T}$ cells had a reduced ability to cause GVHD, suggesting the involvement of CerS6 on T cell function. It has been reported that a decrease in TCR expression levels leads to a reduction in T cell response following TCR stimulation (27). TCR affinity could be another factor, as the presence of a strong or weak TCR leads to proinflammatory or antiinflammatory responses, respectively (28). Many biological aspects influence 
A

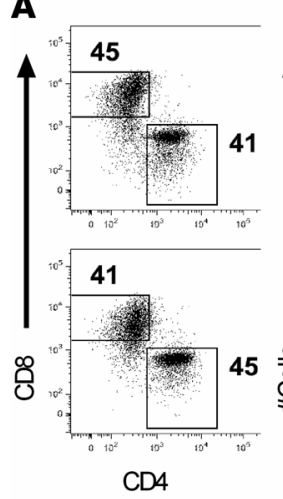

CD4

E

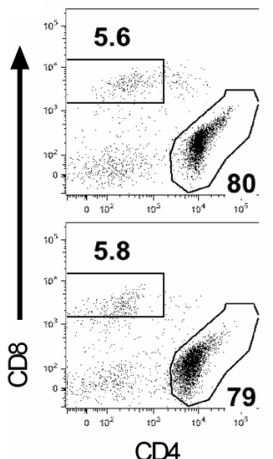

CD4

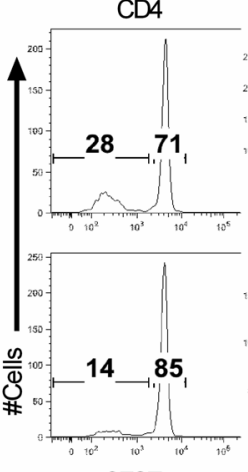

CFSE
Human PBMCs

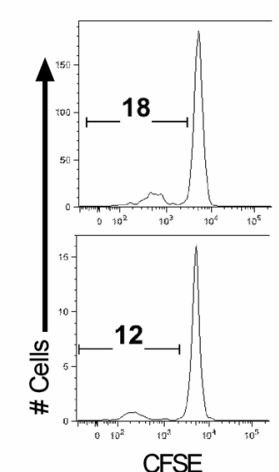

B

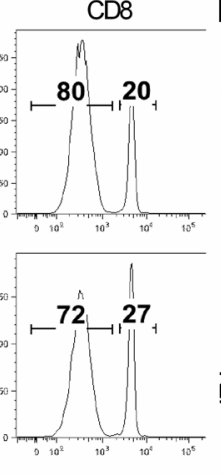

CD4
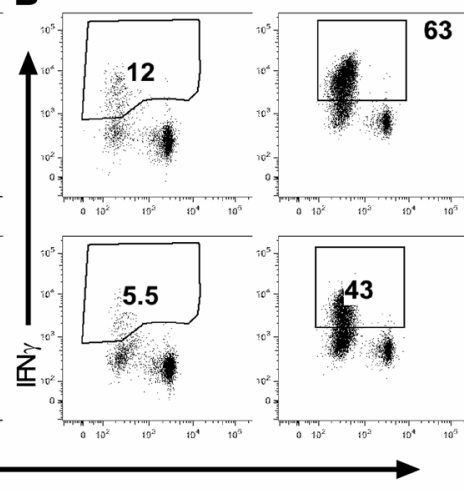

$\mathbf{F}$

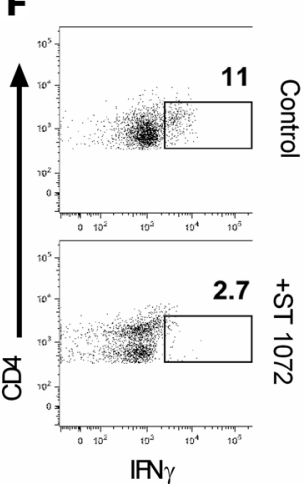

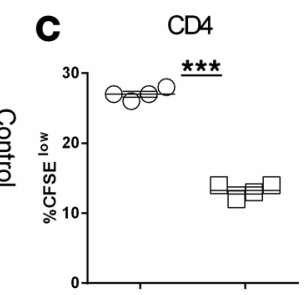
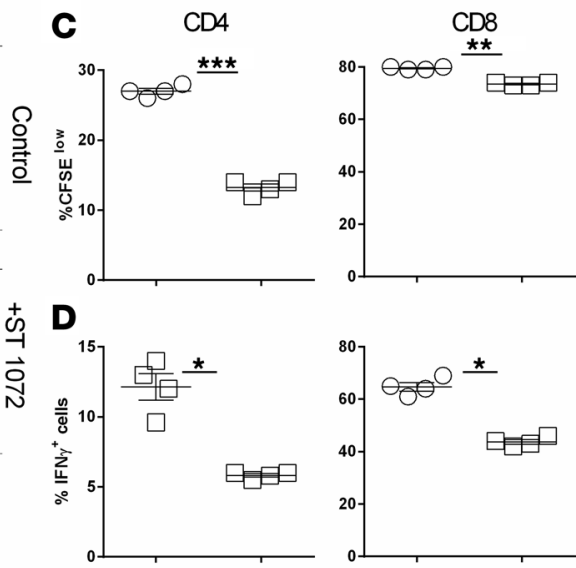

G

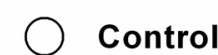

+ST1072

Figure 9. Effects of ceramide synthase 6 inhibition on T cell allogeneic responses. CFSE-labeled T cells from WT or ceramide synthase 6 (CerS6) KO mice were stimulated with allogeneic APCs in the presence or absence of $50 \mu \mathrm{M} \mathrm{ST1072} \mathrm{for} 5$ days. Cells were subjected to FACS staining and analyzed for T cell proliferation and cytokine expression. (A and B) CFSE dilution and percentage of IFN- $\gamma^{+}$on gated CD4+ or CD8 ${ }^{+}$cells. (C and D) CFSE-diluted or IFN- $\gamma^{+}$cells (mean \pm SD). CFSE-labeled human T cells were stimulated with human DCs generated from a HLA-mismatched donor for 5 days in the presence or absence of $50 \mu \mathrm{M}$ ST1072. Cells were subjected to FACS staining and analysis for proliferation and IFN- $\gamma$ production. (E and F) representative flow figures of CFSE dilution and percentages of IFN- $\gamma^{+}$cells on gated donor CD4 cells T cells. (C) The mean \pm SD for CFSE-diluted and IFN- $\gamma^{+}$cells, respectively. Data shown are 1 of 3 independent experiments. Significance was determined by Student's $t$ test. ${ }^{*} P<0.05$, ${ }^{* *} P<0.01,{ }^{* *} P<0.001$.

the polarization of T cells, including factors collectively termed "strength of stimulation," such as peptide dose and duration of TCR engagement (28). Ceramides are known to modulate TCR responsiveness, and CerS6 KO T cells have a reduced TCR response, reflected by a reduction of tyrosine phosphorylation and TCR/CD3-PKC $\theta$ colocalization after TCR engagement. We hypothesized that CerS6 bioactivity could effect TCR repertoire/TCR affinity, which normally mediates $\mathrm{T}$ cell differentiation and Th cell responses $(29,30)$. We demonstrated that genetic deletion or pharmacologic inhibition of CerS6 suppresses T cell proliferation and differentiation into Th1 cells both in vivo and in vitro, which supports our notion that the effect of C16-cer on TCR signaling is directly linked to T cell responses. It is commonly believed that donor $\mathrm{T}$ cell infiltration into target organs is a prerequisite for GVHD development. Chemokine receptors and integrins play important roles in T cell migration to GVHD target organs (29). There were significantly fewer CerS6 KO T cells and proinflammatory cytokines in recipient livers than in their WT counterparts, even though chemokine and chemokine receptors, especially $\alpha 4 \beta 7$ and CXCR3, are comparable (data not shown). Decreased $\mathrm{T}$ cell expansion and/or migration to target organs likely contributed to the reduced pathogenicity of CerS6 KO T cells during the induction of GVHD. Of clinical relevance, we demonstrated that CerS6 KO T cells were partially dispensable for the T cell-mediated GVL effect in a preclinical BMT model. The effect of CerS6 deficiency was obvious not only in allogeneic BMT models, but also in a syngeneic $\mathrm{T}$ cell transfer model of colitis. These observations further support the notion that TCR responsiveness in CerS6 KO T cells was reduced. These data are consistent with distinct functions of ceramides with various different fatty acid chain lengths generated by CerS1-CerS6 (31). For example, while CerS2/ C24-ceramide is implicated in the regulation of liver function (32), CerS1-generated C18-ceramide is associated with nervous system physiology and function through the regulation of Purkinje cells (33). CerS3- 
generated ultra-long sphingolipids play key roles in the homeostasis of skin barrier function (34), whereas deficiency of CerS4 is associated with skin disorders such as irreversible alopecia $(35,36)$.

The regulation of TCR expression is an important mechanism by which T cell responsiveness is controlled, and membrane rafts are the "effector" sites in T cell signaling (37). Upon stimulation, these rafts cluster into an immunological synapse $(38,39)$ that harbors key proteins, including TCR, CD3, PKC $\theta$, ZAP-70, etc. $(40,41)$. The synapse is believed to sustain TCR engagement and T cell signaling (22). Reports have shown that ceramides influence cell fate by participating in various signaling pathways, either through modulation of lipid rafts or through direct interaction with downstream effectors. TCR upregulation was long lasting in the presence of ceramide, but, following its removal, TCR expression quickly returned to baseline levels (27). Ceramide induced TCR upregulation in a concentration- and time-dependent manner. Treatment with high concentrations $(>10 \mu \mathrm{M})$ induces cell apoptosis $(42)$, whereas low titration $(<1 \mu \mathrm{M})$ initiates intracellular Akt activation (43). However, recent studies have shown that exogenous ceramide has no detectable effect after a single treatment (44), although increased expression of CerS6 preferentially generates C16-cer (45). Yet, the effect of exogenous C16-cer was quite evident on CerS6 KO T cells; they showed a marked increase in proliferation both in vivo and in vitro. The in vivo supplementation of C16cer also increased production of proinflammatory cytokines, especially IFN- $\gamma$, in CerS6 KO donor T cells. In contrast, WT T cells remained grossly unchanged in the presence or absence of C16-cer in both cases. We reason that the level of endogenous ceramide in WT T cells significantly increased upon allostimulation and might have reached saturation level (Figure 7A). On the contrary, CerS6 KO T cells failed to show any increase in endogenous C16-cer (Figure 7A) after allostimulation, suggesting that additional supplementation of $\mathrm{C} 16$-cer augments $\mathrm{T}$ cell activation, proliferation, and proinflammatory responses.

It is clear from both previous (12) and current observations that CerS6-generated C16-cers play a critical role in regulating different immune cells, including macrophages and $\mathrm{T}$ cells, which in turn can modulate different autoimmune diseases, such as EAE, GVHD, and colitis. Our study establishes that CerS6 and its products markedly influence the pathogenesis of GVHD and that pharmacologically targeting this pathway could be a novel therapeutic strategy in the clinic. We show that blockade of CerS6/S4 via an inhibitor (ST1072) significantly reduced $\mathrm{T}$ cell proliferation and proinflammatory responses under allogeneic stimulation and that this was consistent in both mouse and human T cells (Figure 9, A-D). Although this inhibitor is known to be specific for CerS6 and CerS4 (23), we observed that CerS4 had a minimal effect on $\mathrm{T}$ cell activation and function during an allogenic response and, subsequently, on GVHD, suggesting that the effect of this inhibitor is due to inhibition of CerS6. T cell phenotypes after CerS6 inhibition and in CerS6 KO T cells had similar effects on proliferation and proinflammatory cytokine production, further suggesting that the preventative role of this inhibitor in GVHD is more pertinent to CerS6 blockade, which can be used to attenuate the severity of GVHD while preserving GVL activity. However, in order for further characterization of ceramide synthases, it is imperative to have specific inhibitors for each ceramide synthase, including CerS6.

In conclusion, we observed that TCR engagement upregulates CerS6, which results in de novo generation of C16-cer, which in turn modulates TCR activity by participating in various signaling pathways, either through modulation of lipid rafts and/or through direct interaction with downstream effectors. This signaling promotes activation of ZAP-70 and colocalization of $\mathrm{PKC} \theta$ with the TCR, leading to allogeneic $\mathrm{T}$ cell activation, proliferation, migration, and proinflammatory cytokine production, which ultimately leads to GVHD development. Furthermore, inhibition of CerS6 using ST1072 reverses the stimulatory effect of CerS6 on T cells, as depicted in Supplemental Figure 7. Therefore, we anticipate that, in the near future, the translational feasibility of specifically silencing (inhibiting) CerS6, which could significantly benefit patients with hematological malignancies undergoing allo-HCT, will be achieved.

\section{Methods}

Mice. C57BL/6 (B6; H-2 ${ }^{\mathrm{b}}$, CD45.2), B6.Ly5.1 (CD45.1) BD2F1, BALB/c (H-2 ${ }^{\mathrm{d}}$ ), and Rag1 KO mice were purchased from the National Cancer Institute (Frederick, Maryland, USA) or Jackson Laboratories. CerS6 $\mathrm{KO}$ (46) and CerS4 KO mice on a B6 background were generated by Texas Institute for Genomic Medicine, College Station, Texas, USA. All animals were housed at the Medical University of South Carolina.

Mixed lymphocyte reaction. T cells were purified from B6, CerS4 KO, and CerS6 KO mice and labeled with CFSE (Invitrogen, Molecular Probes Inc.). For in vitro experiments, $0.2 \times 10^{6} \mathrm{~T}$ cells were cocultured with $\mathrm{T}$ cell-depleted $0.6 \times 10^{6}$ splenocytes for 5 days. For in vivo experiments, the T cells were injected i.v. 
into irradiated recipient mice for 4 days. Recipient spleens were excised, and the cells were stained for T cell proliferation and different cytokines by flow cytometry.

$B M T$. T cells were purified from spleen and lymph node cells by negative selection using magnetic beads as previously described (14). MHC-mismatched (B6 $\rightarrow$ BALB/c) and haploidentical (B6 $\rightarrow$ BD2F1) BMT models were used as previously established (15). Briefly, 8- to 10-week-old recipient mice were conditioned with total body irradiation based on weight, at 650-700 cGy (single dose) for BALB/c mice and 1,100-1,200 cGy (split 3 hours apart) for BD2F1 mice using an X-RAD 320 x-ray irradiator (Precision X-Ray) at Medical University of South Carolina. Within 24 hours after conditioning, recipients were i.v. injected with T cell-depleted BM alone, with or without CD44/25-depleted T cells from WT or CerS6 KO donors. Recipient mice were monitored for weight loss and other clinical signs of GVHD twice per week. Clinical scores were tabulated as 5 parameters: weight loss, posture, activity, fur texture, and skin integrity. Individual mice were scored from 0 to 2 for each criterion and from 0 to 10 overall (16). Recipients at the premoribund stage were euthanized and counted for lethality. Representative samples of GVHD target organs were excised from recipients 21 days after BMT and subjected to pathology scoring as previously described $(14,17)$.

A GVL model was established by i.v. injecting luc/neo plasmid-transduced A20 B cell lymphoma cells (A20-luc) (ATCC) on a BALB/c background the day of BMT $\left(2 \times 10^{3}\right.$ A20 cells/mouse). Tumor growth was measured with bioluminescent imaging using a Xenogen IVIS 200 preclinical in vivo imaging system (PerkinElmer) and analyzed by Living Image software (PerkinElmer) as previously described (17). Tumor and GVHD mortality were distinguished by bioluminescent imaging signal intensity and clinical manifestation of GVHD.

Histologic analysis. Representative samples of liver, small intestine, large intestine, lung, and skin were obtained from transplanted recipients 21 days after transplant, fixed in 10\% neutral-buffered formalin, and washed with $70 \%$ ethanol. Samples were then embedded in paraffin, cut into 5 - $\mu$ m-thick sections, and stained with H\&E. A semiquantitative scoring system was used to account for histologic changes consistent with GVHD in the colon, liver, and lung as previously described (47). Data are presented for individual GVHD target organs. All slides for GVHD analysis were coded and read in a blinded fashion (48).

Flow cytometry. Mononuclear cells were isolated from recipient spleens or livers, as previously described $(14,17,18)$, and stained for surface markers and intracellular cytokines using standard flow cytometric protocols. Stained cells were analyzed using FACSDiva software, LSR II (BD Biosciences) and FlowJo (Tree Star). The following antibodies were used for cell surface staining: anti-CD4-V450 (RM45), -APC, and -PEcy7 (BD Biosciences); anti-CD8-PEcy5 (53-6.7), -APCcy7, and -AF700 (BD Biosciences); anti-CD45.1-FITC (A20) and -APC (BD Biosciences); anti-B220-FITC (RA3-682) and -PE (eBioscience); anti-CD44-APC,PE (IM7) (eBioscience); anti-CD62L-Pecy5,-FITC (MEL-14) (eBioscience); CD25-FITC (7D4) and Pecy7 (PC 61.5) (eBioscience); and anti-H2Kb (AF6-88.5.5.3) (eBioscience). Intracellular staining was carried out using anti-IFN- $\gamma-\mathrm{PE}$ or Per-cp 5.5 (XMG1.2; BD Biosciences), anti-IL-4-PE (11B11; BD Pharmingen), anti-IL-5-PE (TRFK5; BD Pharmingen), and anti-Foxp3-PE (FJK-16s; eBioscience) and the appropriate isotype controls. Synthesis of LCL-2 D-erythro-N-PalmitoylSphingosine (D-e-C16-ceramide) was synthesized by the Lipidomics Shared Resource, Synthetic Unit, Medical University of South Carolina, as described previously $(49,50)$.

HPLC-MS/MS analysis of sphingolipids. Lipid extractions and analyses were performed by the Lipidomics Shared Resource, Analytical Unit, Medical University of South Carolina. Briefly, cells were lysed with RIPA buffer. Further preparation of samples and advanced analyses of endogenous bioactive sphingolipids were performed on a ThermoFisher TSQ Quantum liquid chromatography/triple-stage quadrupole mass spectrometer system, operating in a multiple reaction monitoring-positive ionization mode, as previously described (51). Lipid levels were normalized to the level of protein present in samples (picomol/mg protein)

Immunoprecipitation and immunoblots. Primary splenocytes $\left(7 \times 10^{6}\right.$ cells $)$ were incubated with $5 \mu \mathrm{g} /$ $\mathrm{ml}$ anti-CD3 (145-2C11) for 30 minutes at $4^{\circ} \mathrm{C}$. The cells were washed with PBS and incubated with goat anti-hamster (1:100 dilutions) at $37^{\circ} \mathrm{C}$ for indicated time points. The reaction was stopped immediately by adding $1 \mathrm{ml}$ ice-cold PBS containing $0.5 \mathrm{mM}$ EDTA and $2 \mathrm{mM}$ sodium pervanadate $\left(\mathrm{Na}_{3} \mathrm{VO}_{4}\right)$. Cells were washed with PBS and lysed for 45 minutes with lysis buffer containing Triton X-100 lysis buffer containing $50 \mathrm{mM}$ Tris, $\mathrm{pH}$ 7.6, $150 \mathrm{mM} \mathrm{NaCl}, 50 \mathrm{mM} \mathrm{NaF}, 1 \mathrm{mM}$ EDTA, $1.8 \mathrm{mg} / \mathrm{ml}$ iodoacetamide, and a mixture of protease inhibitors (aprotinin, pepstatin, and leupeptin) on ice followed by centrifugation at $16,000 \mathrm{~g}$ for 10 minutes at $4^{\circ} \mathrm{C}$. The supernatant was incubated with protein A/G-Sepharose beads for 2 hours at $4^{\circ} \mathrm{C}$ 


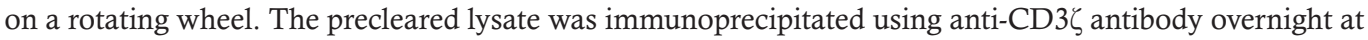
$4^{\circ} \mathrm{C}$ on a rotating wheel followed by incubation with protein A/G-Sepharose beads for 2 hours at $4^{\circ} \mathrm{C}$ on a rotating wheel to precipitate the immune complex. After washing 3 times using lysis buffer, the bound proteins were fractionated on an SDS-PAGE gel, and Western blotting was performed and developed with antiphosphotyrosine antibody (clone 4G10) (EMD Millipore) to detect the bound proteins. One-tenth of the lysate was used for Western blot.

Immunofluorescence. Primary splenocytes $\left(2 \times 10^{6}\right.$ cells) were incubated with $5 \mu \mathrm{g} / \mathrm{ml}$ 145-2C11 (Bio X Cell) for 30 minutes at $4^{\circ} \mathrm{C}$. The cells were washed with PBS and incubated with goat anti-hamster IgG (1:100 dilutions) at $37^{\circ} \mathrm{C}$ for different time points. The reaction was stopped immediately by adding $1 \mathrm{ml}$ ice-cold PBS containing 0.5 mM EDTA and $2 \mathrm{mM}$ sodium pervanadate $\left(\mathrm{Na}_{3} \mathrm{VO}_{4}\right)$. Cells were washed with PBS and incubated with FC blocker CD16/CD32 (BD pharmingen) for 10 minutes followed by staining with antiCD3 antibody (Pharmingen) for 30 minutes at $4^{\circ} \mathrm{C}$. After washing with PBS, cells were stained with Alexa Fluor 488-conjugated secondary antibody (Jackson Immuno Research) for 30 minutes at $4^{\circ} \mathrm{C}$ followed by PBS wash. Cells were fixed and permeabilized using 2\% paraformaldehyde (20 minutes) and $0.1 \%$ Triton $\mathrm{X}-100$ in $1 \times$ PBS (pH 7.4) for 10 minutes. The cells were then blocked with $1 \%$ BSA dissolved in $1 \times$ PBS $\left(\mathrm{pH}\right.$ 7.4) for 1 hour. Cells were incubated overnight at $4^{\circ} \mathrm{C}$ with $\mathrm{PKC} \theta$ antibody (Santa Cruz Biotechnology). After washing, cells were stained with Alexa Fluor 594-conjugated secondary antibody (Jackson Immuno Research) for 30 minutes at $4^{\circ} \mathrm{C}$. Immunofluorescence was performed using an Olympus FV10 microscope with 488- and 594-nm channels for visualizing green and red fluorescence. Images were taken at $\times 63$ magnification. At least 4 random fields were selected for images.

Statistics. For comparison of recipient survival among groups in GVHD experiments, the log-rank test was used to determine statistical significance. Clinical scores and body weight loss were compared using a nonparametric Mann-Whitney $U$ test. For parametric data, where we used more than two groups, ANOVA, Dunnett's, and/or Bonferroni's test were performed. To compare cytokines levels when analyzing two groups, a 2-tailed Student's $t$ test was performed. $P<0.05$ was considered significant.

Study approval. All mice were housed in a pathogen-free facility at the American Association for Laboratory Animal Care-accredited Animal Resource Center at the Medical University of South Carolina. All animal studies were carried out under protocols approved by the institutional animal care and use committee at the Medical University of South Carolina.

\section{Author contributions}

MHS and XZY participated in research study design, analyzed and interpreted data, and drafted the manuscript. MHS, JH, M. Dany, HN, M. Dai, DB, SS, YW, AD, and SG conducted experiments and acquired data. MHS, DB, BO, AZ, ZS, HS, YJC and XZY edited the manuscript. CL performed pathological analysis. BO provided genetic KO mice. HS provided ST1072 inhibitor.

\section{Acknowledgments}

The authors would like to thank to the Flow Cytometry Core, Small Animal Imaging Core, Lipidomics Shared Resources, and Cell \& Molecular Imaging Facilities at the Medical University of South Carolina for their assistance. The research presented here was supported in part by pilot research funding from the Hollings Cancer Center (support grant P30 CA138313) at the Medical University of South Carolina and the NIH (grants R01 CA118116, R01 CA169116, R01 AI 118305, and R21 CA192202 to XZY and P01-CA203628 and CA173687 to BO).

Address correspondence to: Xue-Zhong Yu, Department of Microbiology and Immunology, HCC350, MSC955, Medical University of South Carolina, 86 Jonathan Lucas Street, Charleston, South Carolina 29425-5090, USA. Phone: 843.792.4756; E-mail: yux@musc.edu.

1. Ferrara JL, Reddy P. Pathophysiology of graft-versus-host disease. Semin Hematol. 2006;43(1):3-10

2. Socié G, Ritz J. Current issues in chronic graft-versus-host disease. Blood. 2014;124(3):374-384

3. Shlomchik WD. Graft-versus-host disease. Nat Rev Immunol. 2007;7(5):340-352.

4. Ferrara JL, Levine JE, Reddy P, Holler E. Graft-versus-host disease. Lancet. 2009;373(9674):1550-1561.

5. Welniak LA, Blazar BR, Murphy WJ. Immunobiology of allogeneic hematopoietic stem cell transplantation. Annu Rev Immunol. 2007;25:139-170. 
6. Ogretmen B, Hannun YA. Biologically active sphingolipids in cancer pathogenesis and treatment. Nat Rev Cancer. 2004;4(8):604-616.

7. Zeidan YH, Hannun YA. The acid sphingomyelinase/ceramide pathway: biomedical significance and mechanisms of regulation. Curr Mol Med. 2010;10(5):454-466.

8. Ben-David O, Futerman AH. The role of the ceramide acyl chain length in neurodegeneration: involvement of ceramide synthases. Neuromolecular Med. 2010;12(4):341-350.

9. Nguyen $\mathrm{HD}$, et al. Metabolic reprogramming of alloantigen-activated T cells after hematopoietic cell transplantation. $J$ Clin Invest. 2016;126(4):1337-1352.

10. Rotolo JA, et al. Cytolytic T cells induce ceramide-rich platforms in target cell membranes to initiate graft-versus-host disease. Blood. 2009;114(17):3693-3706.

11. Becker KA, Riethmüller J, Zhang Y, Gulbins E. The role of sphingolipids and ceramide in pulmonary inflammation in cystic fibrosis. Open Respir Med J. 2010;4:39-47.

12. Schiffmann S, et al. Ceramide synthase 6 plays a critical role in the development of experimental autoimmune encephalomyelitis. J Immunol. 2012;188(11):5723-5733.

13. Grösch S, Schiffmann S, Geisslinger G. Chain length-specific properties of ceramides. Prog Lipid Res. 2012;51(1):50-62.

14. Teichgräber V, et al. Ceramide accumulation mediates inflammation, cell death and infection susceptibility in cystic fibrosis. Nat Med. 2008;14(4):382-391.

15. Bonder CS, Pitson SM. Sphingolipids--who's controlling who in disease? Immunol Cell Biol. 2015;93(9):767-768.

16. Iwabuchi K, Nakayama H, Oizumi A, Suga Y, Ogawa H, Takamori K. Role of ceramide from glycosphingolipids and its metabolites in immunological and inflammatory responses in humans. Mediators Inflamm. 2015;2015:120748.

17. Socié G, Blazar BR. Acute graft-versus-host disease: from the bench to the bedside. Blood. 2009;114(20):4327-4336.

18. Powrie F, Leach MW, Mauze S, Caddle LB, Coffman RL. Phenotypically distinct subsets of CD4+ T cells induce or protect from chronic intestinal inflammation in C. B-17 scid mice. Int Immunol. 1993;5(11):1461-1471.

19. Read S, Malmström V, Powrie F. Cytotoxic T lymphocyte-associated antigen 4 plays an essential role in the function of CD25(+)CD4(+) regulatory cells that control intestinal inflammation. J Exp Med. 2000;192(2):295-302.

20. Coudronniere N, Villalba M, Englund N, Altman A. NF-kappa B activation induced by T cell receptor/CD28 costimulation is mediated by protein kinase C-theta. Proc Natl Acad Sci USA. 2000;97(7):3394-3399.

21. Monks CR, Kupfer H, Tamir I, Barlow A, Kupfer A. Selective modulation of protein kinase C-theta during T-cell activation. Nature. 1997;385(6611):83-86.

22. Bi K, et al. Antigen-induced translocation of PKC-theta to membrane rafts is required for T cell activation. Nat Immunol. 2001;2(6):556-563.

23. Schiffmann S, et al. Inhibitors of specific ceramide synthases. Biochimie. 2012;94(2):558-565.

24. Nixon GF. Sphingolipids in inflammation: pathological implications and potential therapeutic targets. BrJ Pharmacol. 2009;158(4):982-993.

25. Anderson BE, et al. Memory CD4+ T cells do not induce graft-versus-host disease. J Clin Invest. 2003;112(1):101-108.

26. Zhang P, Wu J, Deoliveira D, Chao NJ, Chen BJ. Allospecific CD4(+) effector memory T cells do not induce graft-versus-host disease in mice. Biol Blood Marrow Transplant. 2012;18(10):1488-1499.

27. Menné C, et al. Ceramide-induced TCR up-regulation. J Immunol. 2000;165(6):3065-3072.

28. Boyton RJ, Altmann DM. Is selection for TCR affinity a factor in cytokine polarization? Trends Immunol. 2002;23(11):526-529.

29. Wysocki CA, Panoskaltsis-Mortari A, Blazar BR, Serody JS. Leukocyte migration and graft-versus-host disease. Blood. 2005;105(11):4191-4199.

30. Sundrud MS, Nolan MA. Synergistic and combinatorial control of T cell activation and differentiation by transcription factors. Curr Opin Immunol. 2010;22(3):286-292.

31. Deng X, et al. Ceramide biogenesis is required for radiation-induced apoptosis in the germ line of C. elegans. Science. 2008;322(5898):110-115.

32. Pewzner-Jung Y, et al. A critical role for ceramide synthase 2 in liver homeostasis: II. Insights into molecular changes leading to hepatopathy. J Biol Chem. 2010;285(14):10911-10923.

33. Spassieva SD, et al. Ectopic expression of ceramide synthase 2 in neurons suppresses neurodegeneration induced by ceramide synthase 1 deficiency. Proc Natl Acad Sci USA. 2016;113(21):5928-5933.

34. Jennemann R, et al. Loss of ceramide synthase 3 causes lethal skin barrier disruption. Hum Mol Genet. 2012;21(3):586-608.

35. Ebel $\mathrm{P}$, et al. Ceramide synthase 4 deficiency in mice causes lipid alterations in sebum and results in alopecia. Biochem $J$. 2014;461(1):147-158.

36. Peters F, et al. Ceramide synthase 4 regulates stem cell homeostasis and hair follicle cycling. J Invest Dermatol. 2015;135(6):1501-1509.

37. Janes PW, Ley SC, Magee AI. Aggregation of lipid rafts accompanies signaling via the T cell antigen receptor. J Cell Biol. 1999;147(2):447-461.

38. Monks CR, Freiberg BA, Kupfer H, Sciaky N, Kupfer A. Pillars article: Three-dimensional segregation of supramolecular activation clusters in T cells. Nature. 1998. 395: 82-86. J Immunol. 2015;194(9):4061-4065.

39. Grakoui A, et al. The immunological synapse: a molecular machine controlling T cell activation. Science. 1999;285(5425):221-227.

40. Hayashi K, Altman A. Protein kinase C theta (PKCtheta): a key player in T cell life and death. Pharmacol Res. 2007;55(6):537-544.

41. Saito T, Yokosuka T, Hashimoto-Tane A. Dynamic regulation of T cell activation and co-stimulation through TCR-microclusters. FEBS Lett. 2010;584(24):4865-4871.

42. Furlong SJ, Ridgway ND, Hoskin DW. Modulation of ceramide metabolism in T-leukemia cell lines potentiates apoptosis induced by the cationic antimicrobial peptide bovine lactoferricin. Int J Oncol. 2008;32(3):537-544.

43. Pozo D, Valés-Gómez M, Mavaddat N, Williamson SC, Chisholm SE, Reyburn H. CD161 (human NKR-P1A) signaling in NK cells involves the activation of acid sphingomyelinase. J Immunol. 2006;176(4):2397-2406.

44. Kue CS, Jung MY, Cho D, Kim TS. C6-ceramide enhances interleukin-12-mediated T helper type 1 cell responses through a cyclooxygenase-2-dependent pathway. Immunobiology. 2012;217(6):601-609. 
45. Tirodkar TS, et al. Expression of ceramide synthase 6 transcriptionally activates acid ceramidase in a c-Jun N-terminal Kinase (JNK)-dependent manner. J Biol Chem. 2015;290(21):13157-13167.

46. Ebel $\mathrm{P}$, et al. Inactivation of ceramide synthase 6 in mice results in an altered sphingolipid metabolism and behavioral abnormalities. J Biol Chem. 2013;288(29):21433-21447.

47. Liang Y, et al. Beta2 integrins separate graft-versus-host disease and graft-versus-leukemia effects. Blood. 2008;111(2):954-962.

48. Haarberg KM, et al. Pharmacologic inhibition of PKC $\alpha$ and PKC $\theta$ prevents GVHD while preserving GVL activity in mice. Blood. 2013;122(14):2500-2511.

49. Yamamoto T, Hasegawa H, Hakogi T, Katsumura S. Versatile synthetic method for sphingolipids and functionalized sphingosine derivatives via olefin cross metathesis. Org Lett. 2006;8(24):5569-5572.

50. Szulc ZM, et al. Tailoring structure-function and targeting properties of ceramides by site-specific cationization. Bioorg Med Chem. 2006;14(21):7083-7104

51. Bielawski J, Pierce JS, Snider J, Rembiesa B, Szulc ZM, Bielawska A. Sphingolipid analysis by high performance liquid chromatography-tandem mass spectrometry (HPLC-MS/MS). Adv Exp Med Biol. 2010;688:46-59. 